\title{
Gradient Nanostructure and Residual Stresses Induced by Ultrasonic Nano-crystal Surface Modification in 304 Austenitic Stainless Steel for High Strength and High Ductility
}

\author{
Chang $\mathrm{Ye}^{1^{*}}$, Abhishek Telang ${ }^{2}$, Amrinder S. Gill ${ }^{2}$, Sergey Suslov ${ }^{3}$, Yaakov Idell ${ }^{4}$, Kai \\ Zweiacker ${ }^{4}$, Jörg M.K. Wiezorek ${ }^{4}$, Zhong Zhou ${ }^{5}$, Dong Qian ${ }^{5}$, Seetha Ramaiah Mannava ${ }^{2}$, \\ Vijay K. Vasudevan ${ }^{2}$
}

${ }^{1}$ Department of Mechanical Engineering, University of Akron, Akron, OH 45325

${ }^{2}$ Department of Mechanical and Materials Engineering, University of Cincinnati, Cincinnati, OH 45221-0072

${ }^{3}$ School of Materials Engineering, Purdue University, West Lafayette, IN 47906

${ }^{4}$ Department of Mechanical Engineering and Materials Science, University of Pittsburgh, Pittsburgh, PA 15261

${ }^{5}$ Department of Mechanical Engineering, University of Texas at Dallas, Richardson, TX 75080

* Corresponding author: email: cye@ uakron.edu phone: 330-972-4032 Fax: 330-972-6027

\begin{abstract}
In this study, the effects of Ultrasonic Nano-crystal Surface Modification (UNSM) on residual stresses, microstructure changes and mechanical properties of austenitic stainless steel 304 were investigated. The dynamic impacts induced by UNSM leads to surface nanocrystallization, martensite formation, and the generation of high magnitude of surface compressive residual stresses (-1400 MPa) and hardening. Highly dense deformation twins were generated in material subsurface to a depth of $100 \mu \mathrm{m}$. These deformation twins significantly improve material work-hardening capacity by acting both as dislocation blockers and dislocation emission sources. Furthermore, the gradually changing martensite volume fraction ensures strong interfacial strength between the ductile interior and the two nanocrystalline surface layers and thus prevents early necking. The microstructure with two strong surface layers and a compliant interior embedded with dense nanoscale deformation
\end{abstract}


twins and dislocations leads to both high strength and high ductility. The work-hardened surface layers (3.5 times the original hardness) and high magnitude of compressive residual stresses lead to significant improvement in fatigue performance; the fatigue endurance limit was increased by $100 \mathrm{MPa}$. The results have demonstrated that UNSM is a powerful surface engineering technique that can improve component mechanical properties and performance.

Keywords: Ultrasonic Nano-crystal Surface Modification (UNSM); ultrasonic peening; deformation twins; gradient microstructure; deformation-induced martensite; residual stresses; fatigue performance; precession electron diffraction (PED).

\section{Introduction:}

Generating a nanocrystalline layer at the material surfaces can lead to significant improvement in mechanical properties and thereby their performance. Many mechanical surface processing techniques have been reported to induce surface nanocrystallization, for example, by surface mechanical attrition treatment (SMAT) [1-3], shot peening (SP) [4], ultrasonic shot peening (USP) [5,6], laser shock peening (LSP) [7-14], etc. Surface properties (wear resistance [15][16], corrosion resistance [17], biocompatibility [18], etc) and the bulk mechanical properties (tensile, fracture, fatigue, etc) can be significantly improved through surface nanocrystallization.

Material strength improvement is typically accompanied by loss of ductility. For FCC (face centered cubic) materials, the ductility is strongly affected by the work-hardening capacity, i.e., the capacity to accumulate and store dislocations during tensile deformation. There have been many attempts in the past to produce materials with innovative microstructures that can lead to both high strength and high ductility by introducing, for example, nanoscale precipitates [19-23], highly dense stacking faults [24] and nanotwins [25-28], bimodal microstructure [29-31], hierarchical microstructure [32,33], etc. The idea of hierarchical microstructure originates from nature, where many biological structures possess high strength and high damage resistance [34-37]. Recently, SMAT has been employed to fabricate hierarchical steels that possess both high strength and high ductility [3,32,38].

Ultrasonic Nanocrystal Surface Modification (UNSM) [39,40] is a recently developed technique that utilizes low amplitude ultrasonic frequency vibrations superimposed on static load to induce severe plastic deformation (SPD) that leads to surface nanocrystallization. During UNSM, the sample surface is struck by a tungsten carbide ball attached to an ultrasonic device vibrating at high frequency (10 to $30 \mathrm{KHz})$. The repeated, high frequency strikes cause SPD, which leads to nanocrystallization and compressive residual stresses at and below the material surface to a certain depth that depends on the amplitude, load and strike rate. Unlike the hand-held ultrasonic peening system, the UNSM system is typically integrated in a lathe that holds the part, so that the processing conditions can be precisely 
controlled for high-throughput industrial manufacturing. UNSM has been successfully used to process steel [40,41] and magnesium alloys [42] for improved mechanical properties and performance. A recent study has compared UNSM with LSP and cavitation peening in IN718 SPF (superplastic forming) alloy [12]. However, in-depth investigations of how UNSM affects material microstructure and how this affects the mechanical behavior are still lacking.

Similar to SMAT, UNSM also utilizes mechanical strikes to generate plastic strain on material surface. Unlike SMAT, where neither the intensity nor the density of the strikes can be precisely controlled, both the strike intensity and density can be precisely manipulated for best performance in UNSM. This makes the UNSM process highly repeatable and thus more reliable for industrial applications. In addition, the UNSM system can be easily integrated into modern manufacturing system.

Stainless steels are widely used in a number of industries (aerospace, automotive, nuclear, biomedical, etc) and have been studied extensively. In this study, UNSM processing of austenitic stainless steel (SS) 304 was carried out and the treated samples were characterized by hardness testing, X-ray diffraction (XRD), scanning electron microscopy (SEM) with electron backscatter diffraction (EBSD) and transmission electron microscopy (TEM). The mechanical properties of the 304 stainless steel samples after UNSM processing were evaluated by tensile test and three-point bending fatigue test. The results are presented and discussed in the following.

\section{Experimental details \\ 2.1 Materials}

Samples $(20 \mathrm{~mm}$ X $20 \mathrm{~mm}$ X $1.8 \mathrm{~mm}$ ) were cut by electric discharge machining (EDM) from a plate of AISI 304 stainless steel, the nominal composition of which is $0.08 \mathrm{C}, 1.00 \mathrm{Si}, 2.00$ Mn, 0.045 P, 0.03 S, 18.0-20.0 Cr, 8.0-10.5 Ni, and balance Fe (all wt.\%).

\subsection{Ultrasonic Nano-crystal Surface Modification Experiments}

In the UNSM process, a tungsten carbide ball (diameter $2.38 \mathrm{~mm}$ ) attached to an ultrasonic device scans over the surface while striking it at high frequency (10 to $30 \mathrm{kHz}$ ). During the strike, the depth that the tungsten carbide ball moves into the target material is called the amplitude, which typically ranges from 10 to $40 \mu \mathrm{m}$. At the same time, a static load (typically 10 to 50 Newton) is applied to the ball against the material surface. The parameters in the UNSM process include: the static load, the amplitude of the strike, the scan speed, the intervals between neighboring scans, and the ultrasonic peening frequency. Detailed description of UNSM has been provided in $[39,40]$.

In this study, the UNSM experiment was carried out by an LM-520 UNSM system with the conditions of static load of $20 \mathrm{~N}$, amplitude of $10 \mu \mathrm{m}$, frequency of $20 \mathrm{kHz}$, and scanning speed of $3000 \mathrm{~mm} / \mathrm{second}$. The interval between each pass was $10 \mu \mathrm{m}$. 


\subsection{Microstructural Characterizations:}

The changes brought about by the UNSM process were studied using a number of techniques as below.

Electron Backscatter Diffraction (EBSD/Orientation Imaging Microscopy (OIM): Sample preparation: Cross-section EBSD samples were prepared by mechanical polishing, followed by electro-polishing with $87.5 \%$ methanol and $12.5 \%$ sulfuric acid at a voltage of 24 volts for 20 seconds. EBSD scans with a step size of $0.3 \mu \mathrm{m}$ were carried out using a Genesis 4040 EDAX/TSL EDS/EBSD system in a XL-30 FEI SEM operating at $25 \mathrm{kV}$ at a magnification of $500 X$.

Transmission Electron Microscopy (TEM): The TEM sample at the top surface was prepared by grinding from the side opposite to the UNSM-treated surface, followed by ion-milling using a Fischione Model 1010 system. The in-depth TEM samples were prepared by the Focused Ion Beam (FIB) lift-out method in an FEI Nova-200 FIB system in Birck Nanotechnology Center at Purdue University. TEM observations were carried out by an FEI Titan TEM operated at $300 \mathrm{kV}$ and a Philips/FEI CM20 TEM operated at $200 \mathrm{kV}$.

TEM-based Orientation Imaging Microscopy (OIM) Analysis: Nanoscale lateral spatial resolution OIM analysis has been performed by automated acquisition and indexing of precession electron diffraction (PED) patterns with a JEM2100F TEM equipped with the DIGISTAR/ASTAR system from NanoMEGAS at the University of Pittsburgh. Precessed illumination, $0.6^{\circ}$ precession angle, and electron beam focused to $\sim 3 \mathrm{~nm}$ in diameter at the TEM specimen section surface was scanned across a pre-selected area of interest with step-sizes as small as $2 \mathrm{~nm}$ to obtain maps of PED patterns, which were indexed automatically by optimized matching to computer generated reciprocal lattice based templates of the austenite and martensite phases of interest here. The PED based TEM OIM data sets provide information akin to that available via EBSD based OIM in the SEM but with lateral resolution in areal maps being on the order of $1 \mathrm{~nm}$, limited essentially by the electron beam diameter used in the TEM instrument. The raw data sets of the PED based orientation indexed areal maps were processed and analyzed further with the TSL OIM Data Analysis software.

Phase Analysis: X'Pert MRD PRO X-ray powder diffraction system with $\mathrm{Cu}-\mathrm{K} \alpha$ radiation source and a monochromator was used to analyze the phases in the sample after UNSM. In-depth XRD analysis was carried out after electropolishing the material layer by layer with the same solution as used for the preparation of the EBSD samples.

Residual Stress: Residual stresses were measured by a Proto LXRD system with Cr-Ka radiation and $\{211\}$ peak for martensite phase and $\mathrm{Mn}-\mathrm{K} \alpha$ radiation and $\{311\}$ peak for austenite phase. The X-ray elastic constant $\mathrm{S}_{2} / 2$ used was $6.04 * 10^{-6} \mathrm{MPa}^{-1}$ for the martensite phase and $7.18^{*} 10^{-6} \mathrm{MPa}^{-1}$ for the austenite phase. The diameter of the X-ray beam was $1 \mathrm{~mm}$. 
In-depth residual stresses were measured by electropolishing the material layer by layer. The electropolishing solution was composed of 12.5 volume percent sulfuric acid and 87.5 volume percent methanol. The electropolishing was carried out in an Electro4 Met system from Buehler with a voltage of 24 volts. Strain gradient correction and layer removal corrections were carried out in accordance with SAE J784a standard (residual stress measurement by X-ray diffraction).

\subsection{Mechanical Property Tests:}

Hardness test: The hardness change of the samples was measured by a nano-indentation system (CSM Instruments) with a Berkovich indenter with a maximum load of $100 \mathrm{mN}$ and 10 seconds holding time. An average of five measurements was used for each reported data point.

Tensile test: Tensile test samples were cut by an electro-discharge machine (EDM) from a sheet. Both of two opposite faces of the gauge area were processed by UNSM before tensile test. The tensile test was carried out at room temperature with a strain rate of $1.9 \times 10^{-5} \mathrm{~s}^{-1}$.

Fatigue test: Three-point bending fatigue test was carried out using a MTS Bionix servo-hydraulic fatigue test machine. The loading profile is a sine function and the frequency is $5 \mathrm{~Hz}$ and the stress ratio is 0.1 . The span of the bending fatigue test was $30 \mathrm{~mm}$. All tests were carried out at room temperature and in a laboratory environment. The sample thickness was $2.8 \mathrm{~mm}$ with a gauge width of $10 \mathrm{~mm}$ and a gauge length of $40 \mathrm{~mm}$. The fatigue samples were cut by EDM from a large sample processed by UNSM on both sides.

\section{Results and Analysis}

3.1 Near-Surface and Through-the-depth Phase distribution after UNSM

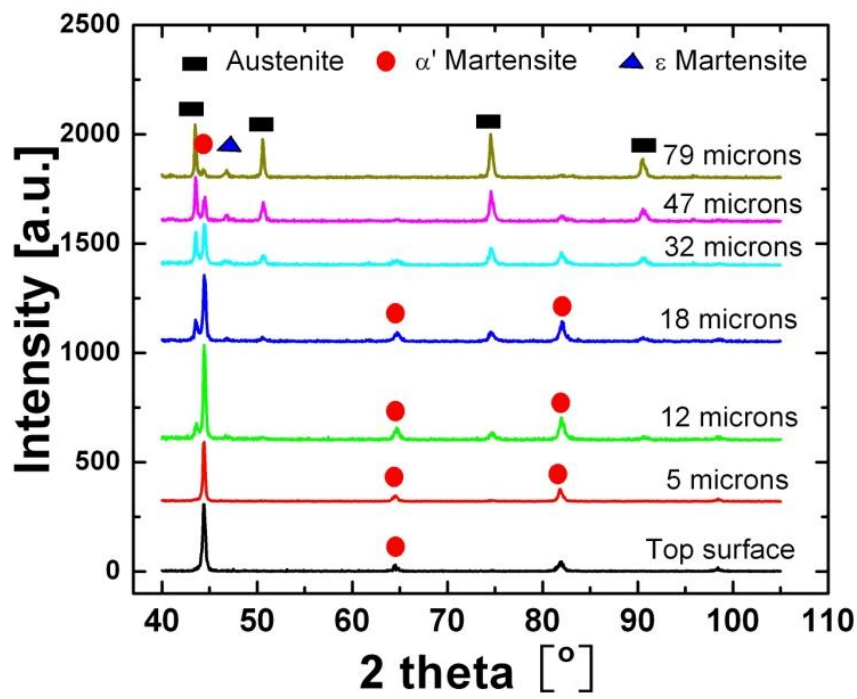


(a)

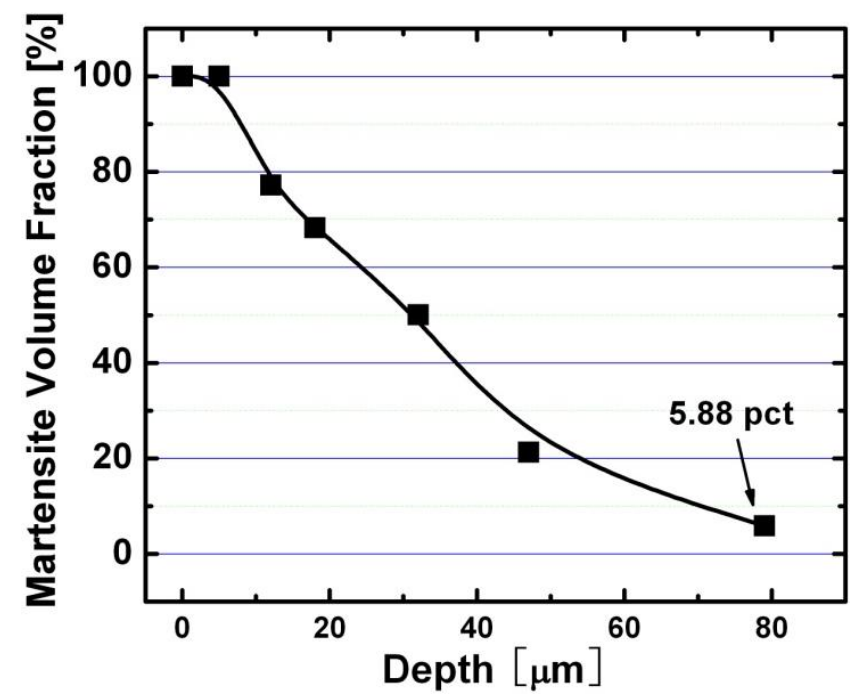

(b)

Fig. 1 (a) XRD patterns at different depth of SS 304 after UNSM, (b) in-depth volume fraction of the martensite after UNSM

Like many other mechanical surface processing techniques, the plastic deformation and strain induced by UNSM assumes a gradient nature, with the top surface having the highest plastic strain, followed by a gradual decrease in strain deeper into the material. Thus, the martensite volume fraction also assumes a gradient with distance from the surface. To investigate the in-depth martensite volume fraction, sequential layer removal by electrochemical polishing and XRD analysis was performed. Figure 1a shows the XRD patterns recorded from the UNSM sample with $10 \mu \mathrm{m}$ interval at different depths. At the top surface and $5 \mu \mathrm{m}$ below, the structure is fully martensite, which is similar to the results reported in SS 304 processed by SMAT [2] and ball milling [43]. At $12 \mu \mathrm{m}$ below the surface, the austenite phase peak at around $75^{\circ} 2$-theta appears. With increasing depth into the material, the martensite volume fraction decreases while the austenite phase volume fraction increases gradually. In addition, an $\varepsilon$-martensite peak at around $47.5^{\circ}$ 2-theta appears from $12 \mu \mathrm{m}$ below surface, and its intensity increases gradually with depth into the material. At $79 \mu \mathrm{m}$ below the surface, the microstructure is almost fully austenitic except for the $\varepsilon$-martensite peak at around $47.5^{\circ}$ 2-theta and a small $\alpha^{\prime}$ martensite peak at around $44.5^{\circ} 2$-theta. Transformation from austenite to $\varepsilon$-martensite at the subsurface has been observed in SS 304 subjected to SMAT by Chen and co-workers [38]. Figure $1 \mathrm{~b}$ shows the martensite volume fraction at different depths, estimated by the direct comparison method by calculating the contribution of different phases to the XRD peak intensities [44]. The martensite volume fraction at the top surface is $100 \%$ and decreases sharply deeper into the material. At around $100 \mu \mathrm{m}$ below the surface, the material is almost purely austenite.

\subsection{Near-Surface and Through-the-Depth Microstructure Observed by Optical Microscopy and EBSD}


The near-surface and through-the-depth microstructure was characterized by optical microscopy, SEM and EBSD. Figure 2 shows optical micrographs of the sample surface before and after UNSM processing. Before UNSM processing, the grain size is around $20 \mu \mathrm{m}$ and sporadic annealing twins can be observed. After UNSM, a more refined microstructure with evidence for extensive plastic deformation can be observed on the surface. The cross-sectional view (Fig. 3a) of the sample shows a gradient microstructure with a SPD layer of around $50 \mu \mathrm{m}$. Higher magnification optical (Fig. 3b) and SEM (Fig. 3c) images of the cross section reveals bent grains and a lot of deformation bands within grains as marked by the arrows.

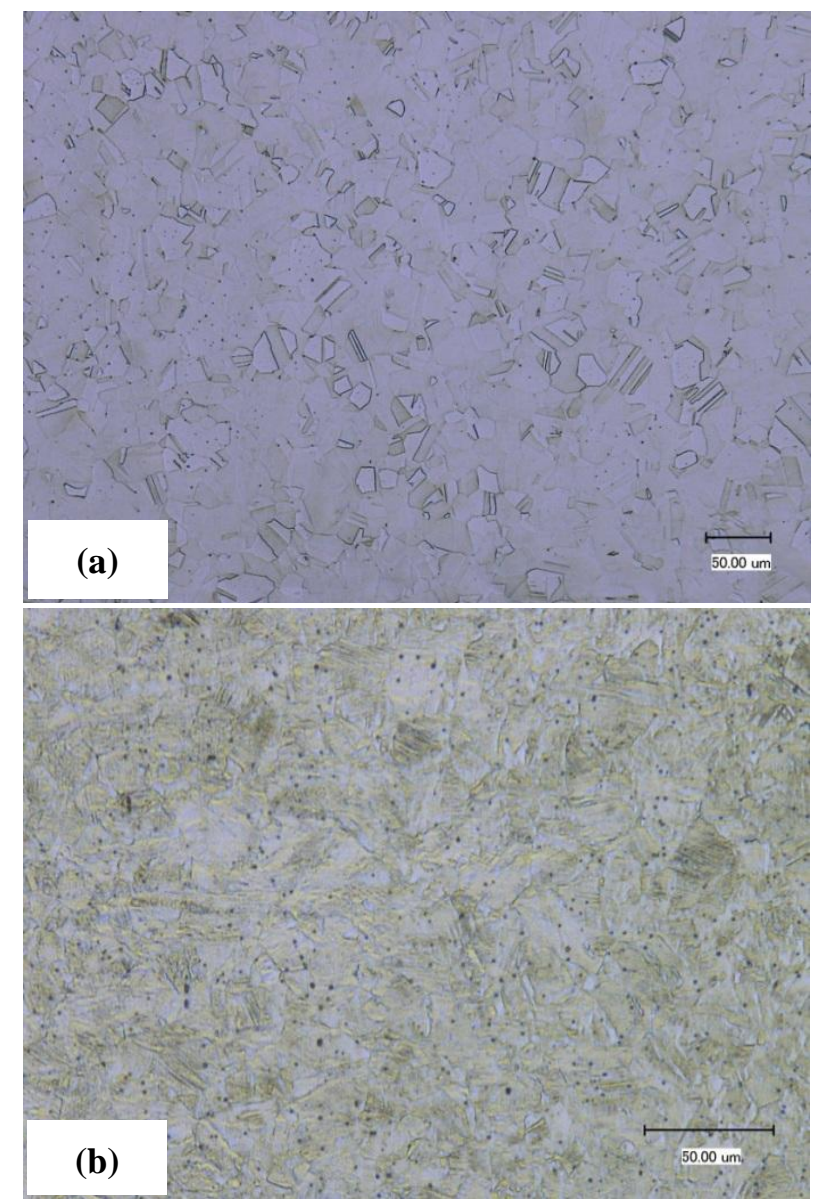

Fig. 2 Optical image at the top surface of the sample before (a) and after (b) UNSM 

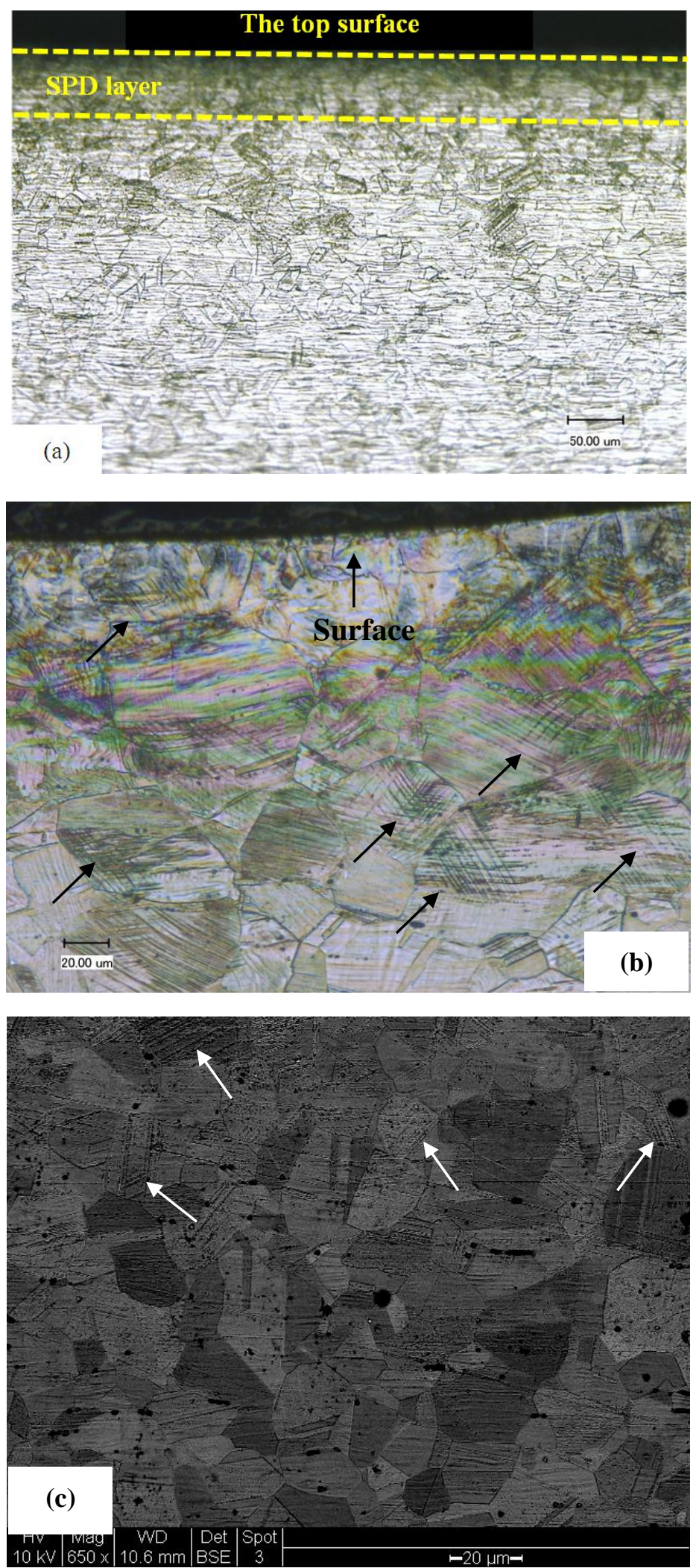

Fig. 3 Optical $(a, b)$ and SEM (c) images showing the cross section microstructure of the sample after UNSM; the arrows point to the deformation bands 

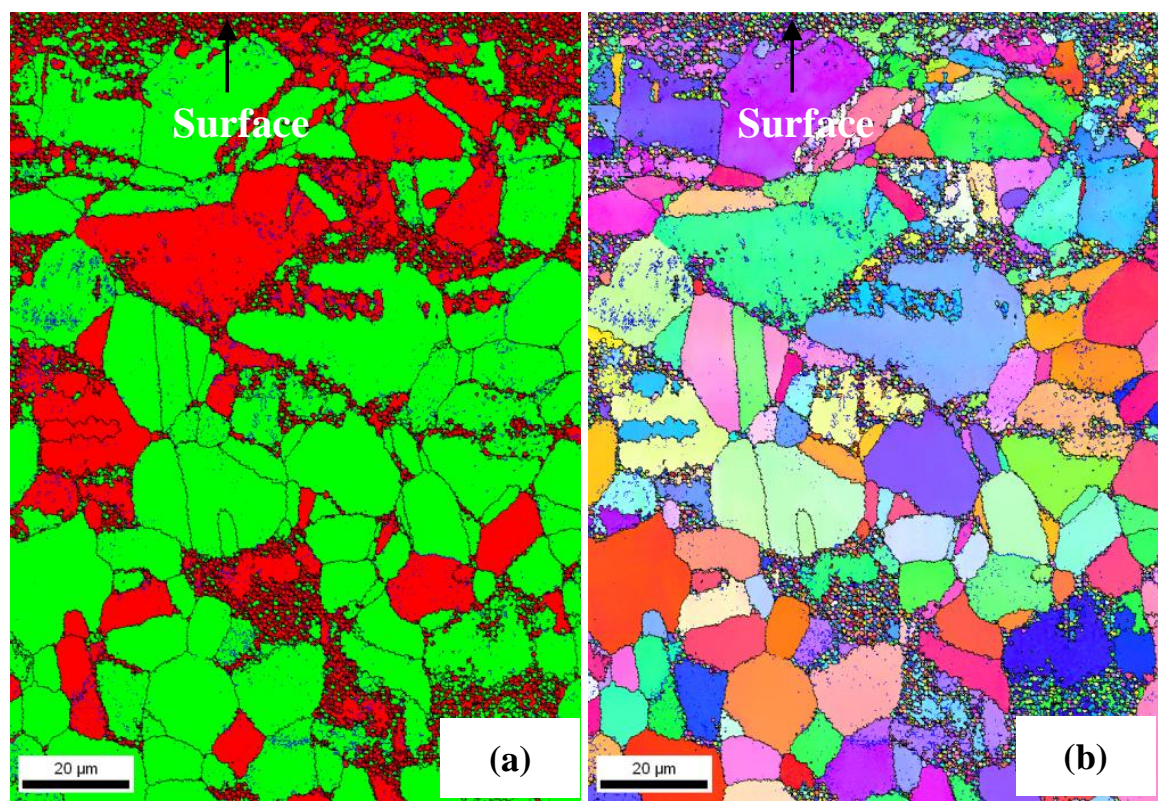

Color Coded Map Type: Inverse Pole Figure [001] Iron (Alpha)
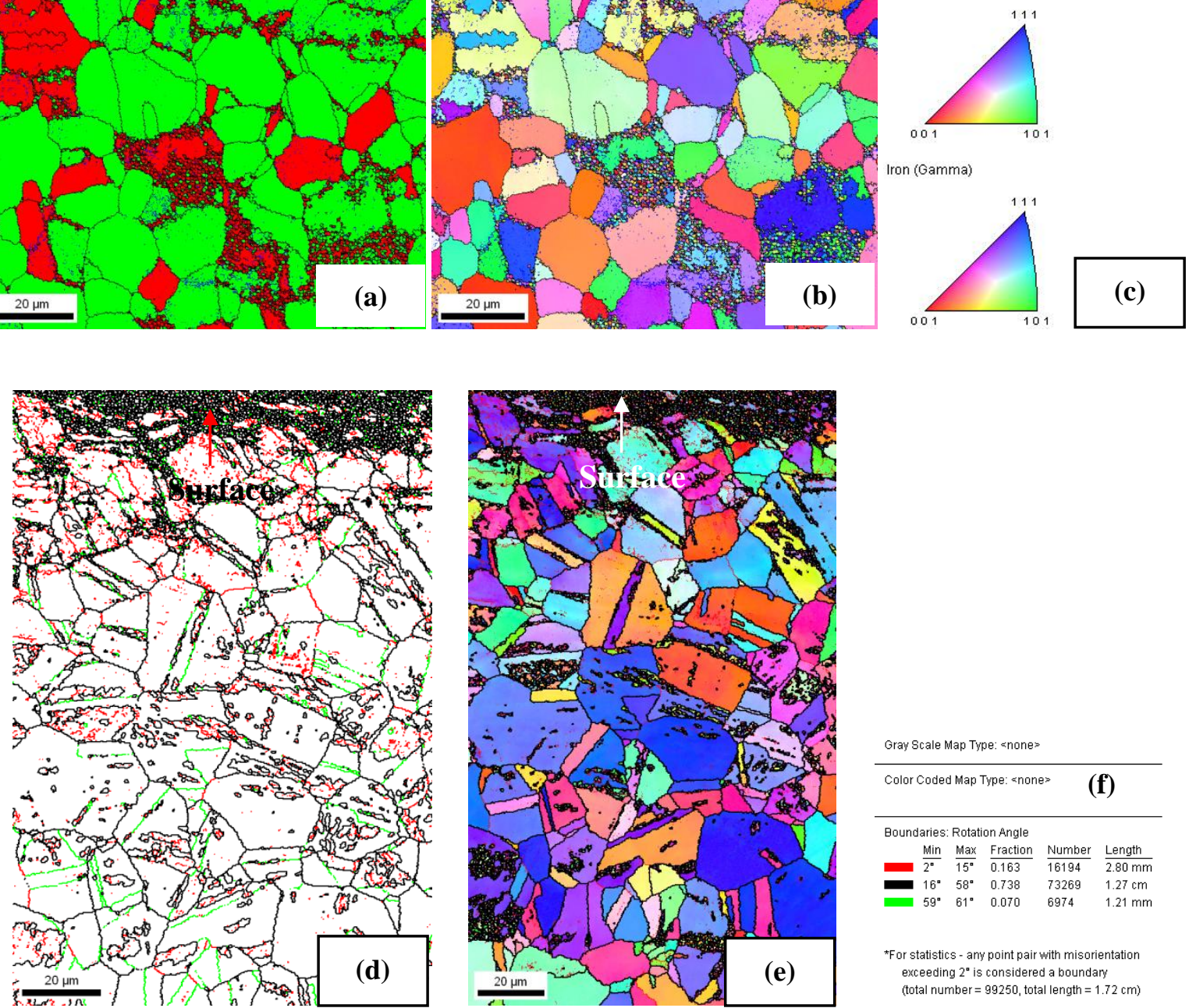

Fig. 4 phase distribution from EBSD analysis in the cross section (all top edges correspond to the top surface of the samples) of the sample after UNSM: (a) phase map: red represents martensite phase, green represents austenite phase, (b) inverse pole figure (IPF) in the same region as in (a), (c) legend of IPF map in (b) and (e), (d) grain boundary map, (e) IPF map of the region in (d), (f) legend of the grain boundary map in (d)

EBSD has been widely used to characterize phase transformations induced by plastic deformation in stainless steels. Figure 4 shows the phase distribution from the EBSD map recorded from the cross-section of the UNSM treated sample. A layer of very refined grains can be observed at the very top surface. In Fig. 4a, the red color represents the martensite phase, whereas the green color represents the austenite phase. The red color of the top layer means that fully martensite phase exists at the top surface, which corroborates well with the XRD result in Fig. 1b. It should be noted that due to the limited resolution of the EBSD 
system, the fine features at the top surface could not be resolved. Thus, precession electron diffraction (PED) in the TEM has been used to further characterize this region and is presented later in this paper.

Deeper into the material, the martensite volume fraction decreases and the austenite volume fraction increases. At the subsurface, small grains exist in-between big grains because most refined grains are generated near the grain boundaries. During plastic deformation, stress concentration occurs at the grain boundaries, which is favorable for martensitic phase transformation. On the other hand, martensitic transformation also contributes to grain refinement [2,38]. This leads to the generation of martensite phase and fine grains along the grain boundaries. Figure $4 \mathrm{~d}$ shows the grain boundary map, where the green colored boundaries represent the twin boundaries. In the very top surface, fine twin boundaries are intermixed with the refined grains. According to Fig. 4f, $7 \%$ in number and $23 \%$ in length of the boundaries are twin boundaries. Figure $4 \mathrm{~b}$ and $4 \mathrm{e}$ show the inverse pole figure (IPF) maps of the grains in the regions in Fig. $4 \mathrm{a}$ and $4 \mathrm{~d}$, respectively. In both figures, random grain orientation can be observed.

\subsection{Top-surface and Sub-surface microstructure observation by TEM and precession electron diffraction (PED)}

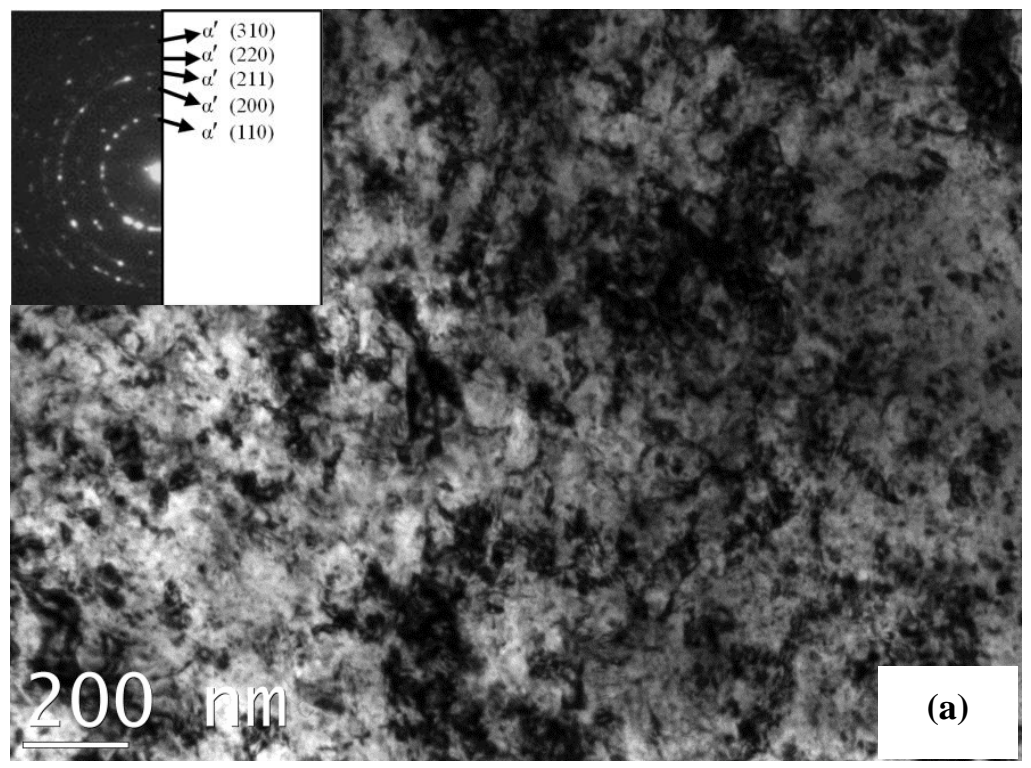




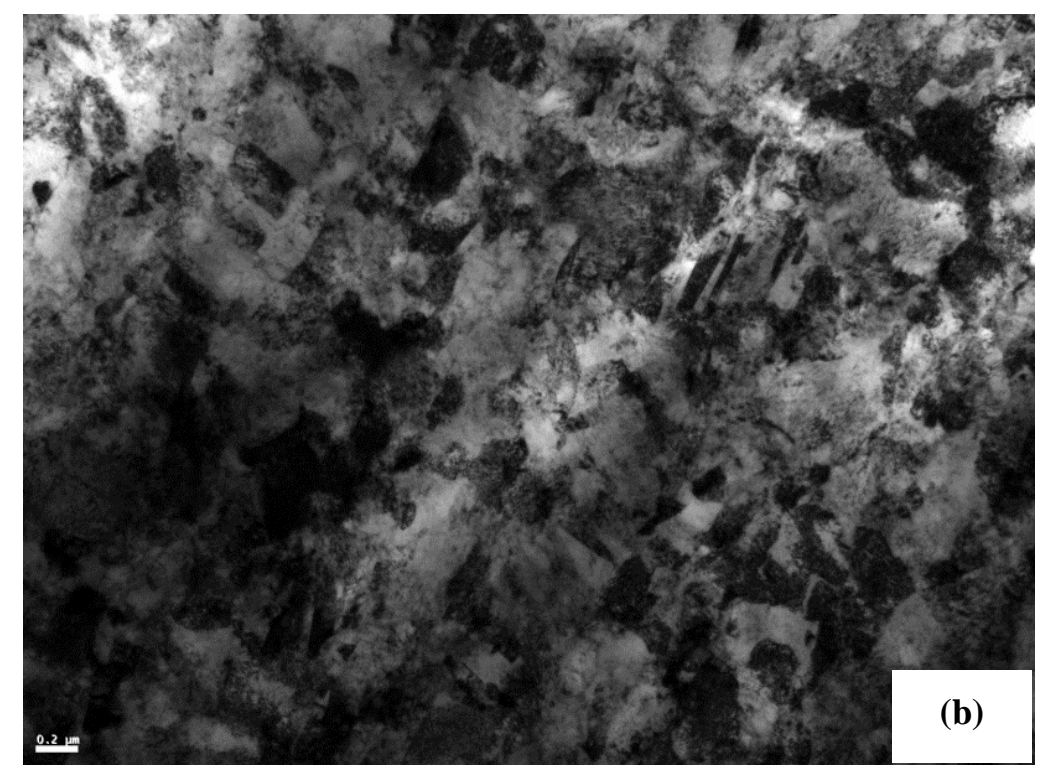

Fig. 5 bright field TEM images from the top surface (a) and $10 \mu \mathrm{m}$ below surface (b) of the sample after UNSM

Figure 5 shows the TEM images from the top surface (Fig. 5a) and $10 \mu \mathrm{m}$ below surface (Fig. $5 b)$ of the SS 304 sample after UNSM. Nano-grains are observed at the top surface. The diffraction pattern recorded from the top surface (inset in Fig 5a) reveals many rings, indicating the existence of the nano-grains, and all the rings were indexed as arising from martensite phase, which corroborates well with the XRD result (Fig. 1b).

Due to the limitation of traditional TEM and EBSD, the grain size at the top surface cannot be precisely characterized. Thus, precession electron diffraction (PED) in a field-emission gun equipped high-resolution TEM (HR-TEM), which has been used successfully previously for the analysis of nano-scale refined and heavily plastically deformed microstructures in steels [45], was used here to accurately characterize the grains in the modified subsurface regions.

Figure 6 shows the PED images from the top surface of the sample after UNSM. Figure 6a shows the IPF map. Figure $6 c$ shows the grain boundary map, from which, we can observe that $11.2 \%$ of the grain boundaries are twin boundaries. Figure $6 \mathrm{e}$ shows the grain size histogram, where we can observe that the majority of the grains are less than $10 \mathrm{~nm}$, while the average grain size at the top surface is $4.1 \mathrm{~nm}$. Figure $6 \mathrm{f}$ shows the phase distribution at the top surface. As expected, fully martensitic phase has been observed. This corroborates well with the XRD (Fig. 1), the EBSD (Fig. 4a) and conventional TEM (Fig. 5a) observations. 


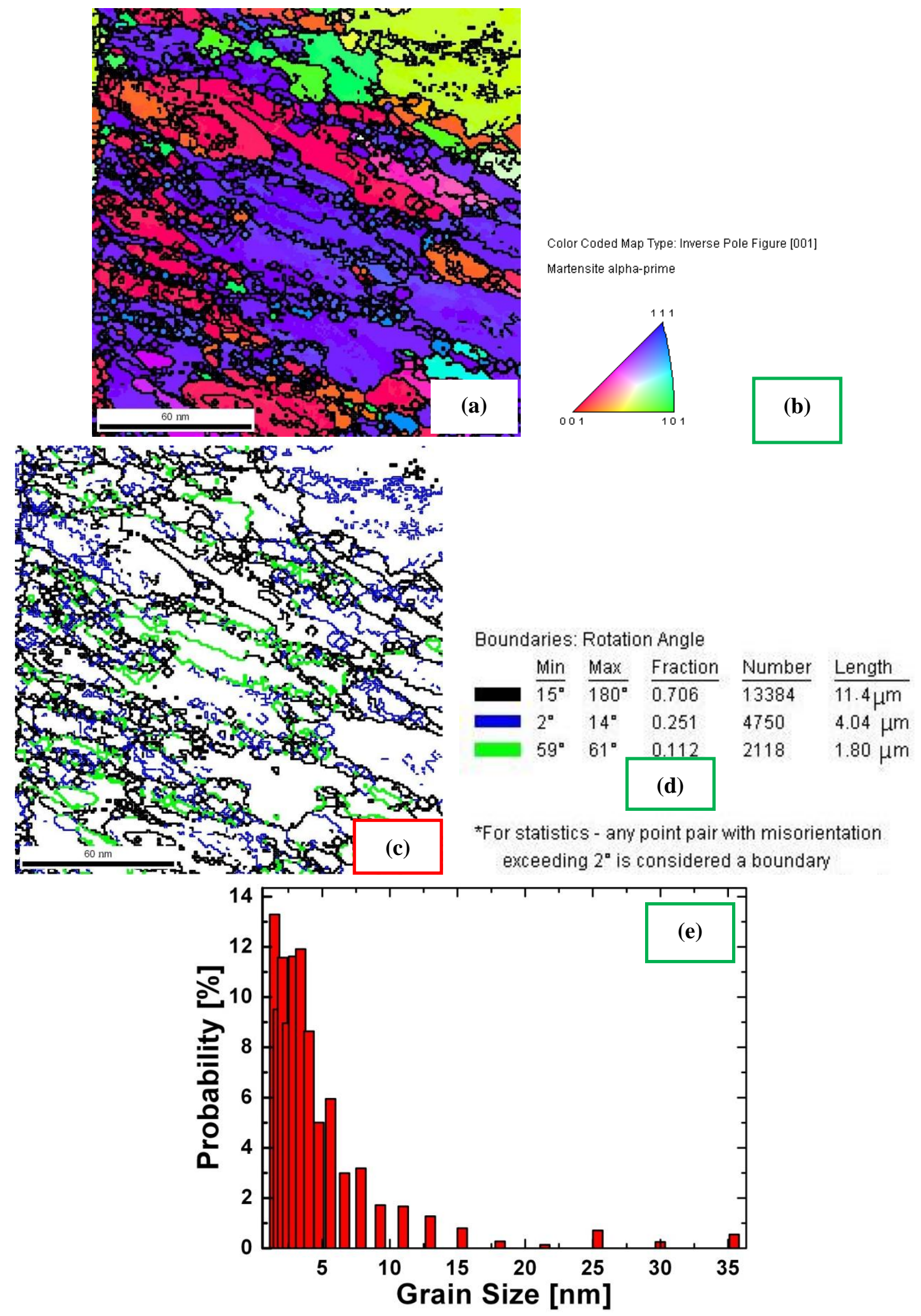



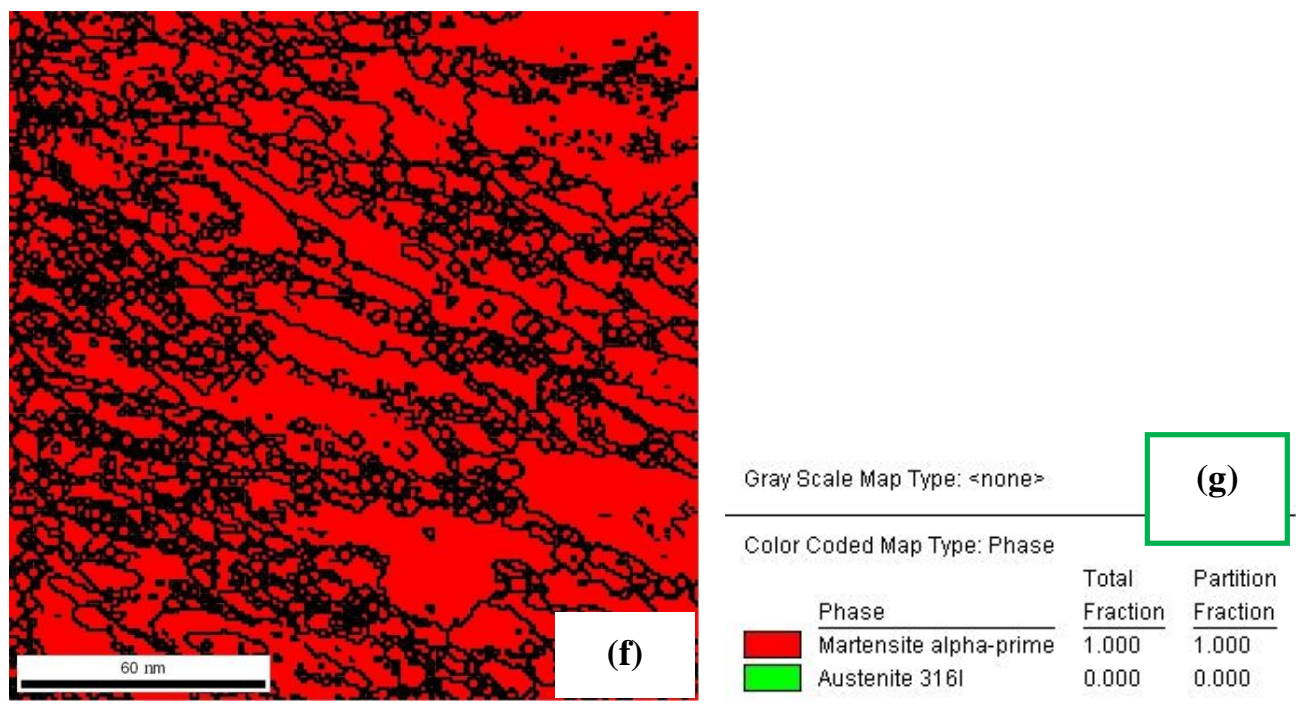

Fig. 6 PED images from the top surface: (a) IPF and the legend (b), (c) grain boundaries map and the legend (d), (e) histogram map of the grains, (f) phase map and the legend (g)

Figure 7 shows the PED images from $10 \mu \mathrm{m}$ below the surface of the sample after UNSM. Figure $7 \mathrm{a}$ shows the IPF map. Figure $7 \mathrm{c}$ shows the grain boundary map, where we can observe that $4.5 \%$ of the grain boundaries are twin boundaries. Figure 7 e shows the grain size histogram, where we can observe that the majority of the grains are less than $50 \mathrm{~nm}$, while the average grain size at $10 \mu \mathrm{m}$ below the surface is $18 \mathrm{~nm}$. Figure $7 \mathrm{f}$ shows the phase distribution at $10 \mu \mathrm{m}$ below the surface. Less than $2 \%$ austenitic phase has been observed, which corroborates well with the results of XRD (Fig. 1b) and the EBSD (Fig. 4a).
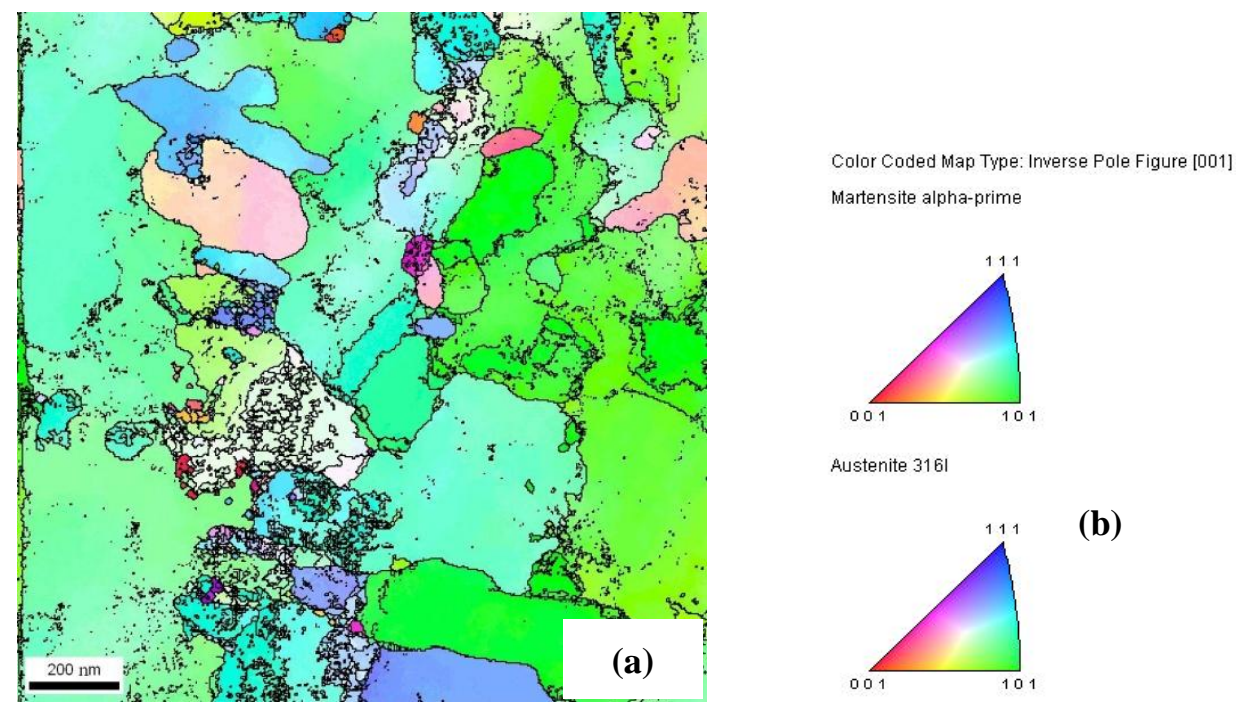

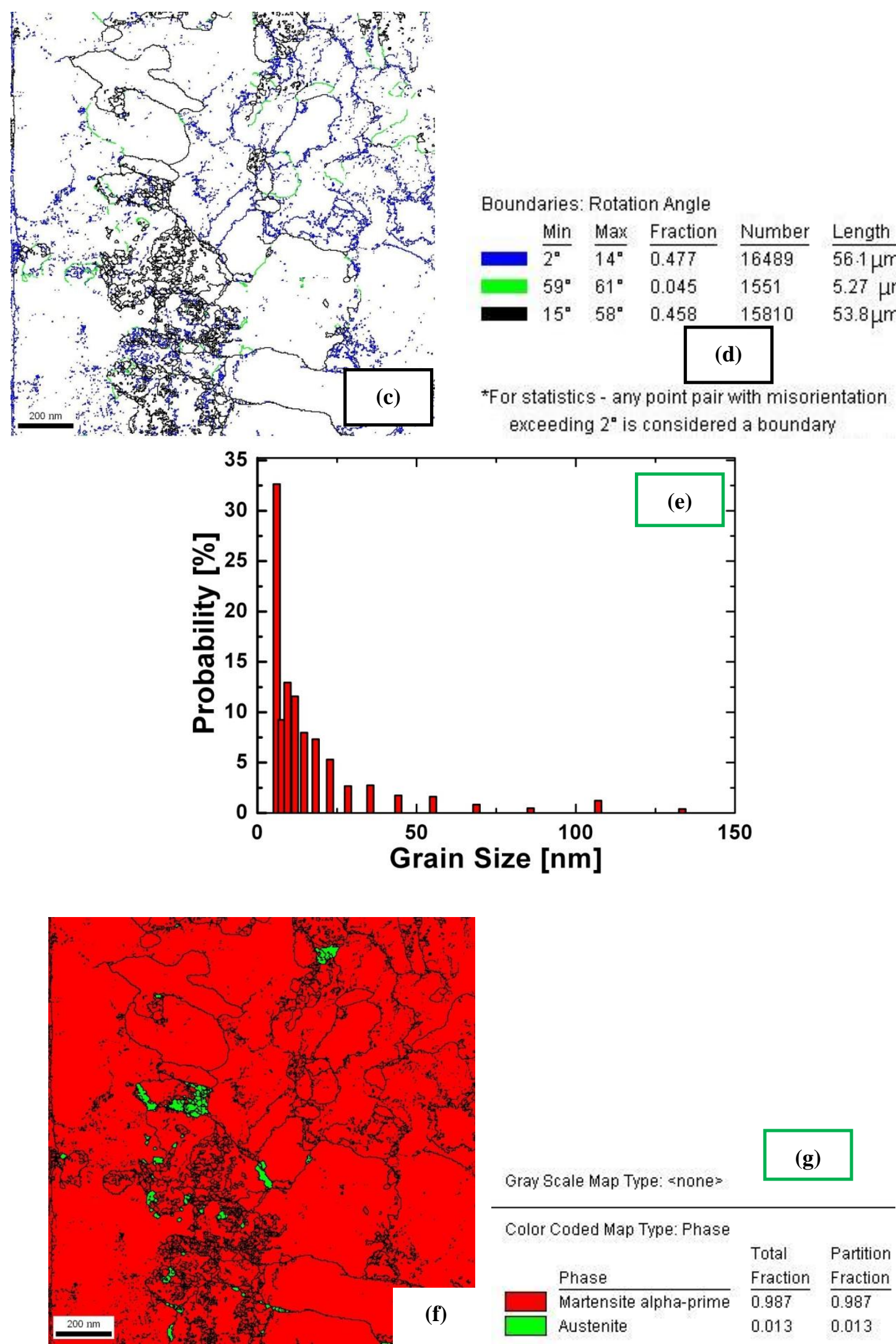

Fig. 7 PED images from $10 \mu \mathrm{m}$ below the top surface: (a) IPF map and the legend (b), (c) grain boundaries map and the legend (d), (e) histogram map of the grains, (f) phase map and the legend $(\mathrm{g})$ 


\subsection{Sub-surface Deformation Twins Observed by TEM}

Due to the gradient nature of the plastic strain induced by UNSM, the microstructure also assumes a gradient nature. Figure 8 shows the TEM images from $20 \mu \mathrm{m}$ below the surface of the UNSM sample. Highly dense deformation twins with different orientations can be observed. Note that deformation twins are present throughout the sample (Fig 8a). Figure 8b shows a dark field image of the deformation twins. Figure $8 \mathrm{c}$ and $8 \mathrm{~d}$ show the deformation twins in another region at different magnifications. The presence of the deformation twins can also be confirmed by the diffraction pattern (Fig. 8e) taken from the region marked by the green ring in Fig. 8d. At this depth $(20 \mu \mathrm{m})$, the accumulation of highly dense dislocations from the high magnitude of the plastic strain leads to stress concentration, which is favorable for deformation twins to nucleate. It should be pointed out that some twins are curved, which could be caused by further straining after the twins are formed. The high magnification image in Fig. 8f reveals that the twin thickness is only a few nanometers, which is due to the high strain rate and high flow stress in the region caused by the dynamic impact loading. As pointed out by Chen and co-workers [38], the higher the flow stress, the thinner the deformation twins. We can also observe the formation of Rhombic blocks (marked in Fig. 8f), which has also been observed in other studies $[2,8]$.
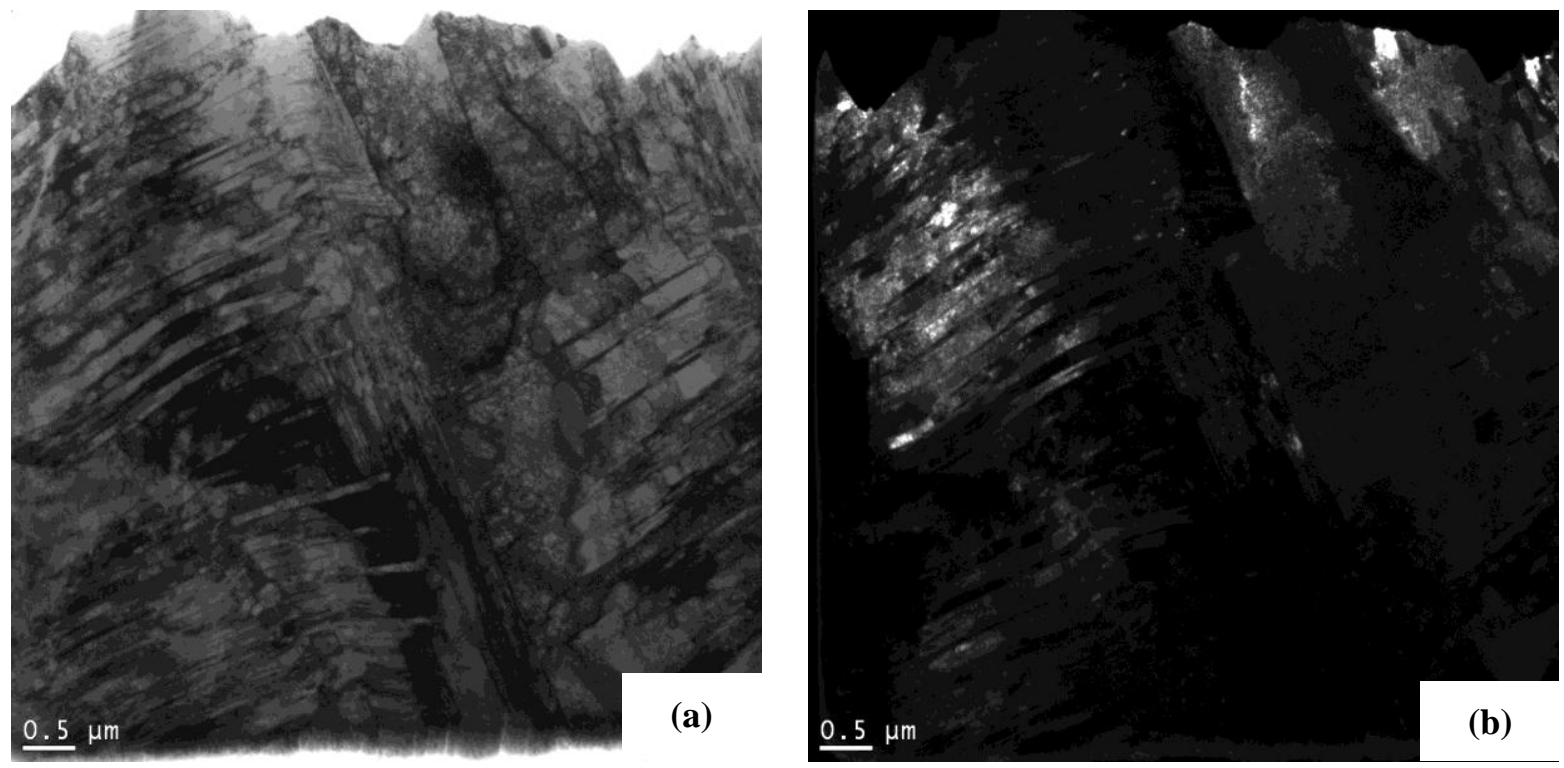

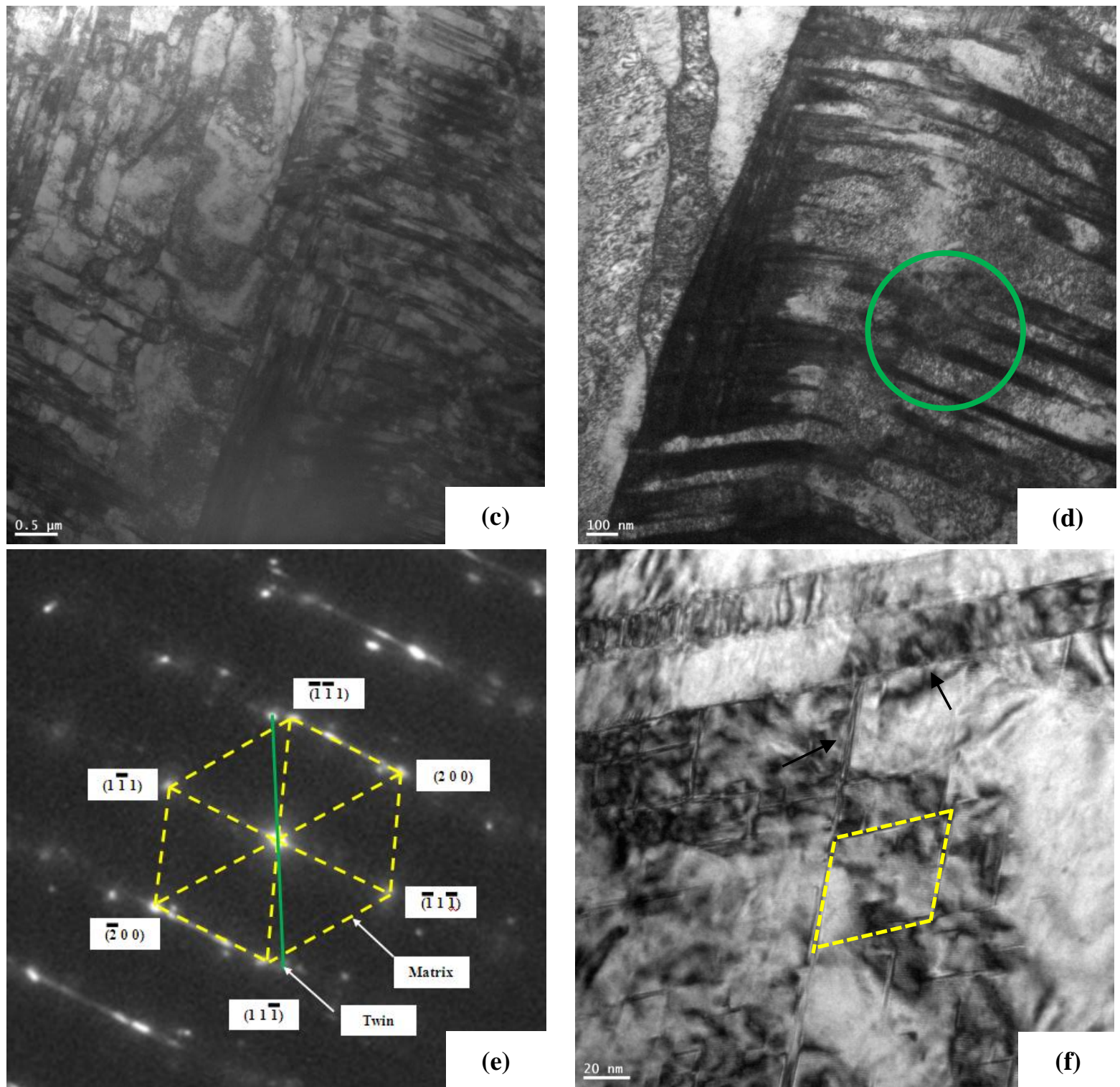

Fig. 8 TEM images of the sample after UNSM at $20 \mu \mathrm{m}$ below the surface showing highly dense deformation twins: (a) bright field image, (b) dark field image, (c) bright field image of another region, (d) high magnification bright field image, (e) diffraction pattern taken from the ring in (d) revealing reflections at $1 / 3\{110\}$ positions from the deformation twins, (f) bright field image at high magnification showing the rhombic blocks

Deeper into the material, the twin density decreases gradually. Figures 9a and Fig. 9b show the TEM images from $50 \mu \mathrm{m}$ below the surface of the UNSM sample. We can still observe some deformation twins, but the density is lower than that in the $20 \mu \mathrm{m}$ sample (Fig. 8). This is because deeper into the material, both the plastic strain and the plastic strain rate are much lower and thus less favorable for deformation twins to form. Similar to the deformation twinning structure in Fig. 8a, twins can also be observed throughout the sample in Fig. 9a. 

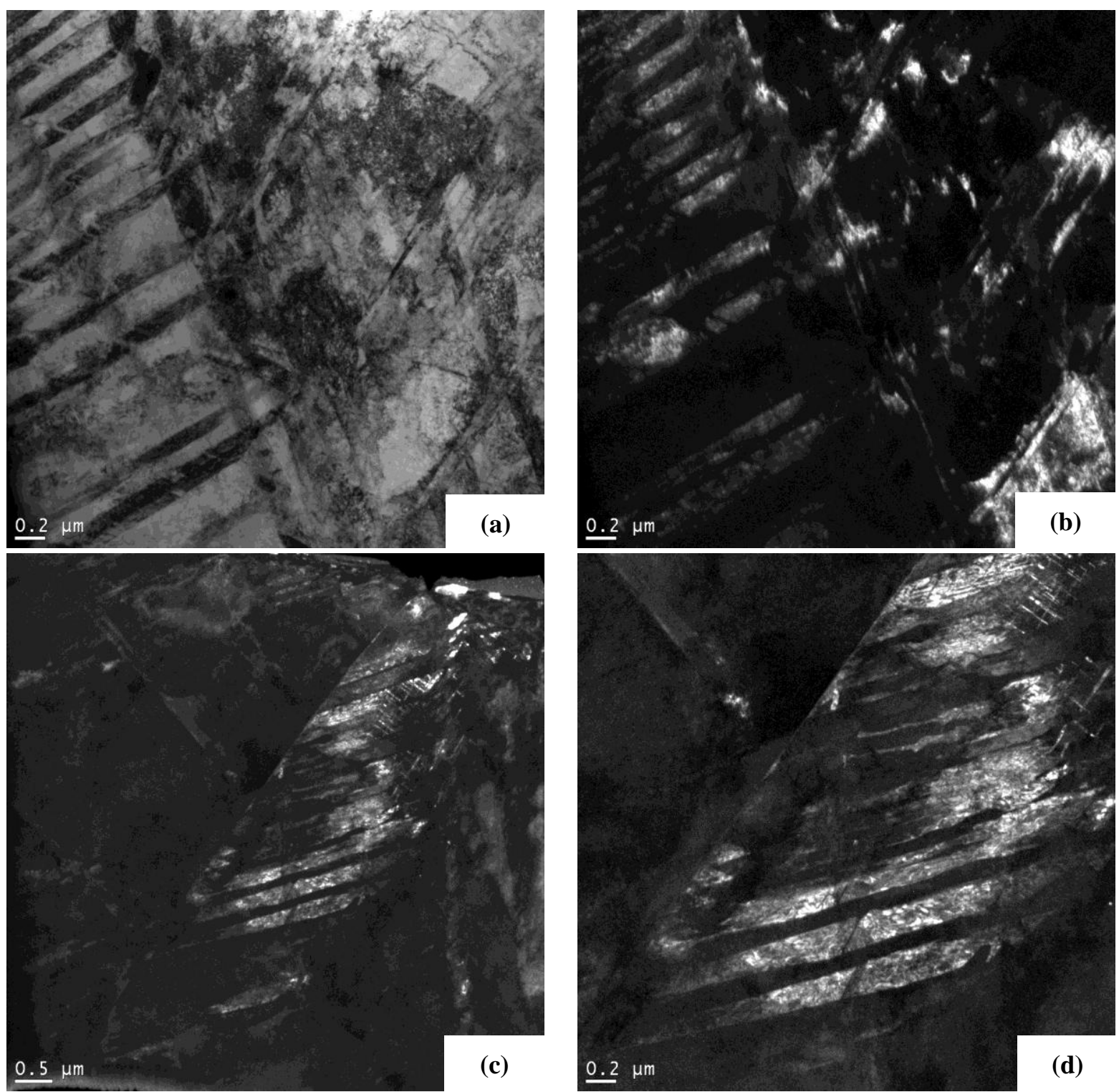

Fig. 9 TEM images of the sample after UNSM at $50 \mu \mathrm{m}$ below the surface: (a) bright field image, (b) dark field image; (c) dark field TEM images of the sample after UNSM at $100 \mu \mathrm{m}$ below the surface: (d) High magnification dark field image of (c)

Figure 9c and Fig. 9d show the microstructure of the TEM sample at $100 \mu \mathrm{m}$ below the surface. Two grains can be observed in the TEM sample, the first at the upper left region, the other at the lower right region. In the first grain, very few deformation twins can be observed, whereas those in the second grain are very dense. The dramatic different deformation twinning behavior stems from the different orientations of the grains relative to the loading direction, which results in different Schmid factors and thus affecting the stress applied to the grain during UNSM striking. It should be noted that the deformation twins appear to originate at the grain boundaries. This is because the grain boundaries are locations where stress concentrations occur and thus are favorable for the nucleation of the deformation twins. 

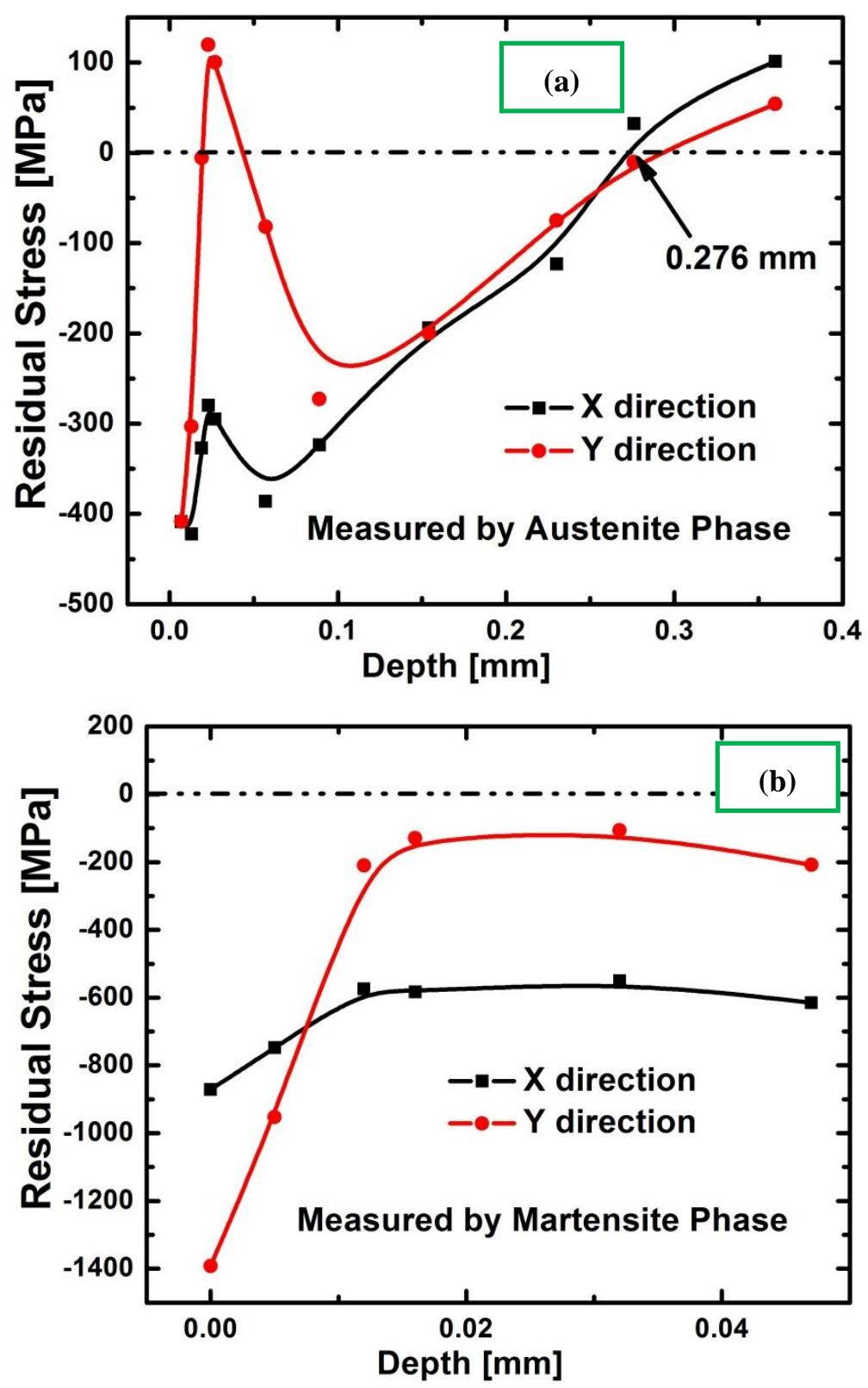

Fig. 10 In-depth residual stresses measured by (a) martensite and (b) austenite phases

The residual stress profile is of interest because it affects component fatigue performance. In this study, XRD was used to measure the residual stresses induced by UNSM. Due to the phase transformation induced by UNSM, two phases (austenite and martensite) exist near the surface. Thus, residual stresses in both the two phases were evaluated. Sequential layer removal by electrochemical polishing followed by XRD residual stress measurement in both martensite and austenite phase were carried out till a depth of $47 \mu \mathrm{m}$. Beyond that only residual stresses in austenite phase were measured because minimal martensitic phase existed. Figure 10a shows the residual stresses in austenite phase in both the $\mathrm{X}$ and $\mathrm{Y}$ directions. The $\mathrm{X}$ direction was defined as the traveling direction of the UNSM tip. The Y direction is perpendicular to the $\mathrm{X}$ direction. Note that the residual stress in the austenite phase on the top surface $(0-5 \mu \mathrm{m})$ could not be measured because only the martensite phase existed there. In Fig. 10a, the residual stresses in $\mathrm{X}$ direction assume a typical distribution seen in most 
surface processing techniques, with a high magnitude of compression at the surface and a gradual decrease deeper from the surface. The depth of the compressive residual stresses generated in SS 304 by UNSM with the parameters in this study is $0.276 \mathrm{~mm}$, close to that of SP and lower than that of LSP. It should be noted that the residual stresses in austenite in the $\mathrm{Y}$ direction have a sharp tensile region at around $25 \mu \mathrm{m}$ below the surface. This has not been observed in most surface processing techniques, such as SP, LSP, SMAT, etc. It is hypothesized the tensile residual stresses region is related to the deformation-induced austenite to martensite phase transformation. Further study is needed to clarify this point.

Figure 10b shows the residual stresses measured in the martensite phase in both the $X$ and the $\mathrm{Y}$ directions. It can be clearly observed the residual stresses magnitudes are dramatically different in the $\mathrm{X}$ and the $\mathrm{Y}$ direction. Also, the residual stresses magnitudes in both the two directions in the martensite phase are much higher than those measured in the austenite phase. For example at $5 \mu \mathrm{m}$ below the surface, the residual stresses measured in the martensite phase in the $\mathrm{X}$ and the $\mathrm{Y}$ direction are -748 and $-952 \mathrm{MPa}$, respectively; at the same depth, the residual stresses measured in the austenite phase in the $\mathrm{X}$ and the $\mathrm{Y}$ directions are both around $-400 \mathrm{MPa}$. It should be noted that the residual stresses measured by both martensite phase and austenite phase are not equi-biaxial.

\subsection{Mechanical Behavior after UNSM}

\section{In-depth Hardness after UNSM}

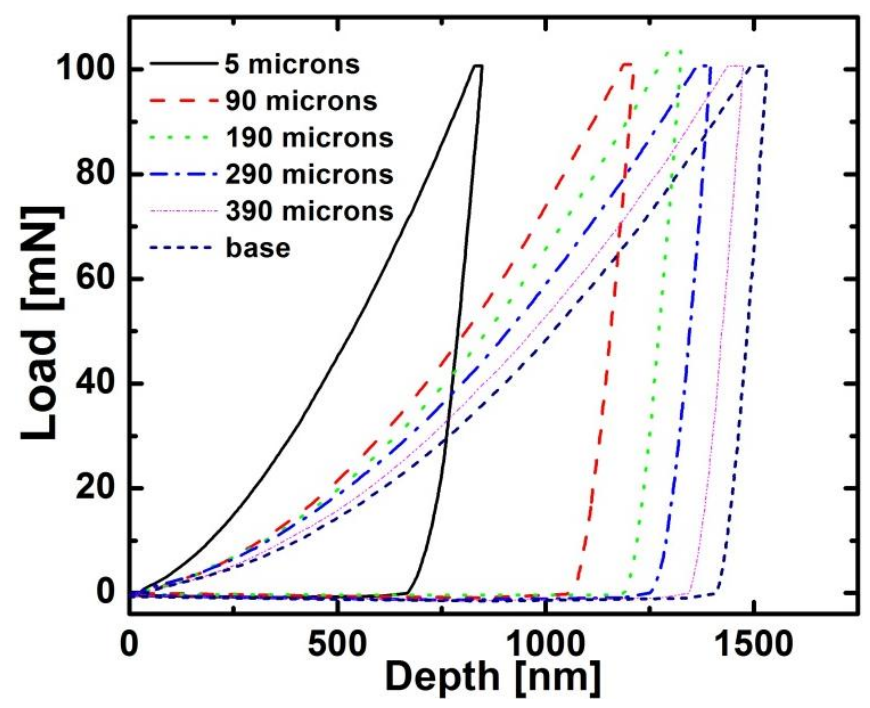

(a) 


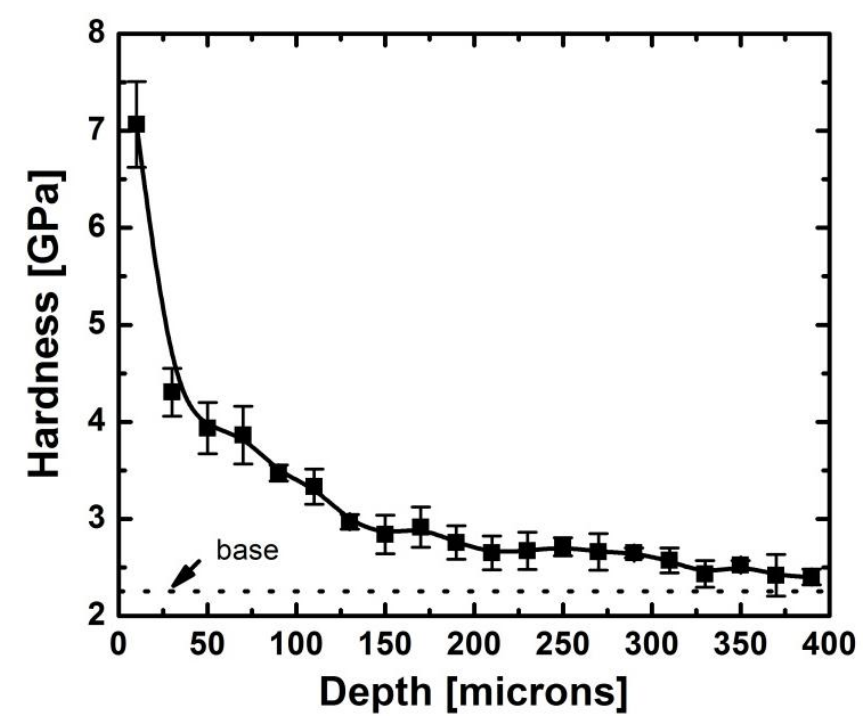

(b)

Fig. 11 (a) representative load-displacement curves from nano-indentation, (b) in-depth indentation hardness from nano-indentation

To investigate the effects of martensite phase transformation and grain refinement on material hardness, nano-indentation test on cross-section of the sample was carried out. Figure 11a shows representative load-displacement curves at different depths from the UNSM-treated sample. The through-the-depth change in hardness is shown in Fig. 11b. At the very top surface, the hardness is as high as $7 \mathrm{GPa}$. The nanoscale grains, the high volume fraction of the martensite phase and the high dislocation density contribute to the high hardness. With increasing distance from the treated surface, the hardness drops quickly. At around $400 \mu \mathrm{m}$ below the surface, the hardness is around $2.2 \mathrm{GPa}$, slightly higher than that of the base material.

\section{Stress-strain curves}

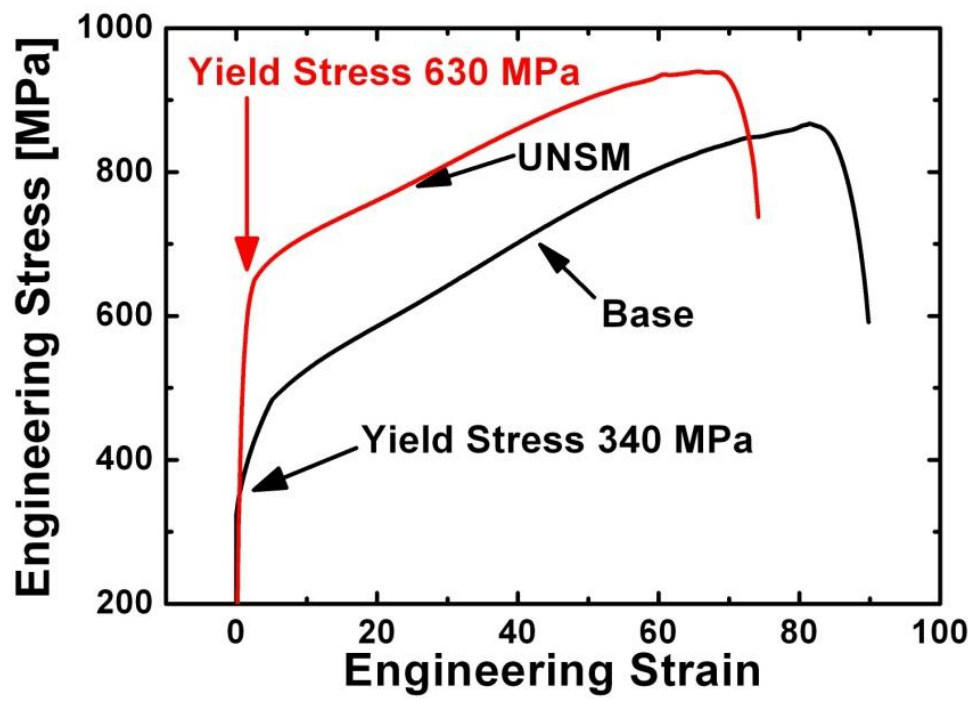

Fig. 12 Engineering stress-strain curves of the samples before and after UNSM treatment 
Material strength and ductility are of interest because they affect component performance in structural applications. Figure 12 compares the engineering stress-strain curves before and after UNSM. The materials yield stress increases from $340 \mathrm{MPa}$ before UNSM to $630 \mathrm{MPa}$ after UNSM, whereas uniform elongation engineering strain correspondingly decreased from $82 \%$ before UNSM to $70 \%$ after UNSM. This means that the strength of the 304 SS increases significantly after UNSM without too much loss in ductility. It is known that the strength and ductility of materials are two mutually-exclusive properties: materials with high strength typically have low ductility. In this study, the 304 SS after UNSM processing has yield strength of $630 \mathrm{MPa}$ while still preserving high ductility (uniform elongation of $70 \%$ ). This is superior to most high strength steels used in engineering.

\section{Fatigue performance:}

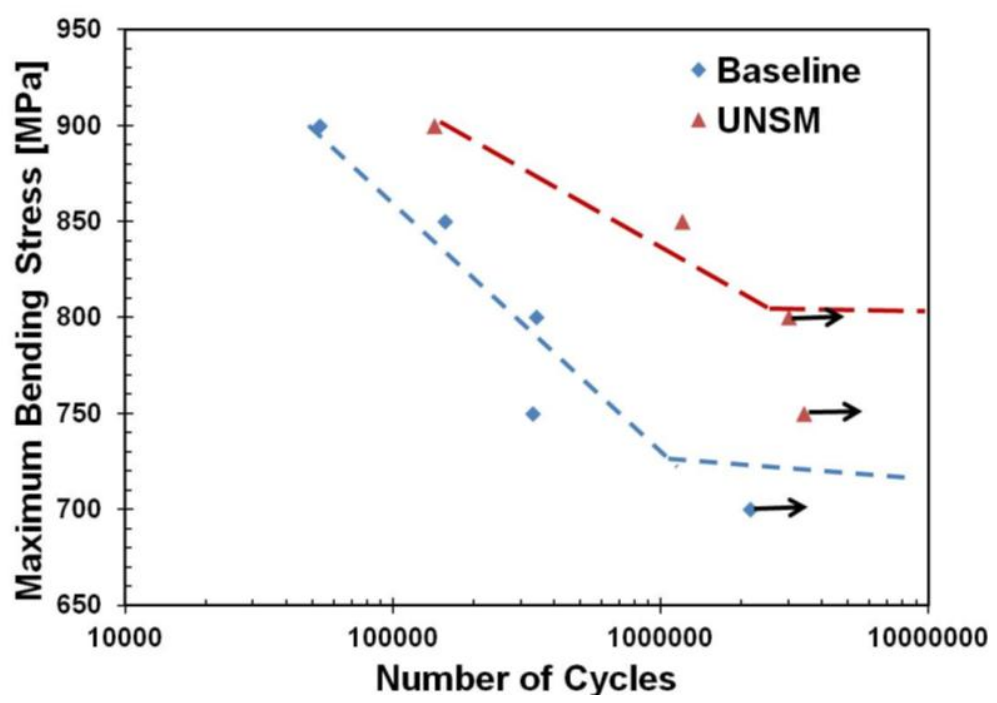

Fig. 13 S-N curves from 3-point bending fatigue test of the samples before and after UNSM

Component fatigue performance affects its long-term stability in structural applications. As can be seen in Figure 13, the fatigue performance increased significantly after UNSM processing of the samples. For example, with a maximum bending stress of $850 \mathrm{MPa}$, the fatigue lives of the samples before and after UNSM are 156,312 and 1,200,000 (run out) cycles respectively, which corresponds to a seven times improvement in fatigue life. The fatigue performance improvement is the comprehensive effect of surface compressive residual stress, surface hardening and microstructural changes. The plastically deformed surface (Fig. 3a) results in high surface hardness (Fig. 11b), which presents a higher resistance to crack initiation. In addition, the high magnitude of surface compressive residual stress, Fig. 10 (400 MPa in austenite phase and $850 \mathrm{MPa}$ in martensite phase) also contributes to the improvement. During the fatigue test, the surface compressive residual stress can decrease the magnitude of the effective tensile stress and thus lead to improved fatigue 
performance. Thus, the fatigue performance improvement in SS 304 by UNSM is a synergistic effect of surface work hardening and surface compressive residual stresses. Enhanced fatigue resistance in $\mathrm{Cu}$ with a gradient nanostructure has been reported by Yang and co-workers [46].

\section{Discussion}

The present study has led to a number of new and interesting findings on the effects of UNSM processing on the near and sub-surface residual stress distributions and microstructural changes and the effects of these on local and bulk mechanical properties, such as hardness, strength, ductility and fatigue properties of 304 austenitic stainless steel. These results are discussed in detail in the following.

\subsection{Generation of deformation twins}

During the plastic deformation of stainless steel, dislocation slip and deformation twinning are two competing process. A critical twinning stress (CTS) must be reached for deformation twinning to occur [47]. According to Chen and co-workers [38], the critical equivalent stress $\left(\sigma_{\mathrm{T}}\right)$ for twinning to occur can be described by:

$\sigma_{T}=6.13 \frac{\gamma_{S F E}}{b_{p}} \quad$ Eq. 1

where $\gamma_{\mathrm{SFE}}$ is the stacking fault energy and $b_{\mathrm{p}}$ is the Burgers vector of a Shockley partial dislocation. Thus, the critical twinning stress can be calculated to be $584 \mathrm{MPa}$ for 304 stainless steel $\left(\gamma_{\mathrm{SFE}}=16 \mathrm{mJm}^{-2}\right.$, and $\left.b_{\mathrm{p}}=0.147 \mathrm{~nm}\right)$. This means that when the critical resolved shear stress in certain grain reaches $584 \mathrm{MPa}$, deformation twinning would initiate. Theoretically, the top surface should have the highest deformation twin density; the twin density should decrease as it goes deeper into the material. No deformation twinning would occur at the depth at which the critical resolve shear stress goes below the critical twinning stress.

According to the TEM observation, deformation twins have been observed from $20 \mu \mathrm{m}$ to $100 \mu \mathrm{m}$ below surface, with the $20 \mu \mathrm{m}$ showing the highest twin density (Fig. 8). However, at the top surface and $10 \mu \mathrm{m}$ below surface, very few deformation twins have been observed in the TEM images, even though very short twin boundaries (the boundaries with $60^{\circ}$ misorientation) have been observed by PED images (Fig. 6c, Fig. 7c). During the UNSM process, deformation twins may have been generated in the top surface at some intermediate stage (Fig. 14). As plastic strain accumulates, the dislocations within the twin-matrix (TM) lamellae increase in density, which results in stress concentration in the TM lamellae, leading to the subdivision of the grains and thus making the twins disappear. This phenomena has also been observed by Lu [8] and Zhang [2]. It has also been suggested in quite a few studies $[2,8,48]$ that, in metallic materials with relatively low SFE, deformation twinning plays an important role in the nanocrystallization process caused by severe plastic strain. During this 
process, the original grains were first sub-divided by mechanical twins; the dislocations generated in-between the TM structure further subdivided the twin lamellae structure into equiaxed nano-crystallites. This finally leads to the nanocrystalline martensitic microstructure in the top surface to $10 \mu \mathrm{m}$ below the surface, which makes long deformation twins hard to observe.

At the subsurface, for example $20 \mu \mathrm{m}$ below the surface, however, the dislocation density generated by plastic strain has not reached the critical point to break the twin boundaries, thus leaving highly dense deformation twins at this depth. Deeper into the material (50 to $100 \mu \mathrm{m}$ ), the strain rate and plastic strain both decrease, leading to relatively lower density of the deformation twins. Thus, the above mentioned mechanisms lead to the occurrence of the maximum twin density at a depth of around $20 \mu \mathrm{m}$.

\subsection{Deformation-induced surface nanocrystallization}

As described in the foregoing, the UNSM process is observed to lead to the formation of nanoscale crystallites at the surface and near-surface regions of the 304 SS material. Deformation-induced nanocrystallization by bulk SPD as well as by other surface treatment processes has been widely reported in the past [49]. The grain refining mechanisms in SS 304 by plastic deformation have been well discussed by Lu et al. [8], Zhang et al. [2] and Chen et al. [38]. Deformation-induced grain refinement in SS 304 originates from dislocation activity [50], deformation twinning [51,52] and martensitic phase transformation [53].

During plastic deformation of stainless steel, dislocation slip and deformation twinning are two competing process. Due to the low stacking fault energy $\left(16 \mathrm{~mJ} / \mathrm{m}^{2}\right)$ of stainless steel 304, it is hard to form dislocation cells through dislocation cross-slip. Rather, planar dislocation arrays, stacking faults with widely separated partial dislocations and twins are more easily formed on the $\{111\}$ slip planes [1]. As more plastic strain accumulates, deformation twins in different directions divide the grains into smaller sections and thus generate some rhombic blocks (Fig. 8f), which eventually leads to nanocrystallization through dynamic recrystallization [8]. Further straining induced by the mechanical strikes generates more and more sub-grain boundaries. As more mechanical strikes are imposed during the UNSM process, the refined grains are rotated, generating randomly distributed nano-grains, as manifested by the ring diffraction pattern in Fig. 5. It should be noted that, even after severe mechanical strikes, some localized deformation twins are still preserved, which are manifested by the nanoscale twin boundaries as presented in Fig. 6c and Fig. 7c, where the green lines represents boundaries with $60^{\circ}$ misorientation, i.e., twin boundaries. It should be noted that this nanocrystallization only occurs at the top surface and to a depth of $10 \mu \mathrm{m}$. Deeper into the material, the magnitude of the plastic deformation decreases to the extent that not enough plastic strain was accumulated to refine the grains to the $10 \mathrm{~nm}$ range.

Martensitic phase transformation also contributes to the nanocrystallization process. Martensitic phase transformation in SS by plastic deformation has been widely studied and 
reported in the past $[2,32,38,54,55]$. Martensite phase transformation is a major method to accommodate plastic strain when stainless steels are subjected to SPD. Martensite phase transformation occurs in this sequence: first, plastic deformation introduces defects in the material in the form of dislocations, stacking faults and twins; second, the intersections of the stacking faults and twins generates plastic strain concentration, and thus serve as embryos for martensite formation; finally, the martensite embryos grow to ultrafine crystallites when the material is subjected to further plastic strain. Typically, the martensite phase formed in this way has very small grain sizes. In the present case, martensite with an average grain size of less than $10 \mathrm{~nm}$ was observed in the near surface region (Fig. 6e). This mechanism explains the presence of large volume fraction of martensite in the near surface region (to $\sim 20 \mu \mathrm{m}$ ). As the amount of plastic strain decreases at greater depths $(50-100 \mu \mathrm{m})$, martensite volume fraction also decreases as observed in the XRD (Fig. 1b) and EBSD (Fig. 4) results presented earlier. It should be noted that martensite phase transformation should not be separated with deformation twinning when explaining the nanocrystallization process, instead they work in synergy to produce surface nanocrystallization.

\subsection{Strength-Ductility-Microstructure Relationship}

\section{Strength:}

The large improvement in material strength after UNSM observed in this study (Fig. 12) could be explained as follows. UNSM involves repeated multidirectional mechanical strikes at high speed onto the material surface. This generates a gradient in plastic deformation with distance from the treated surface, and thus a gradient microstructure (Fig. 14). At the very top surface, large and rapid plastic deformation results in extreme grain refinement to the nanoscale. In the subsurface layer, highly dense deformation twins are generated. In the interior, little plastic deformation occurs and the grain size is largely unaffected. Theoretically, materials strength can be predicted by adding contributions from the reduction in grain size and increase in dislocation density with plastic deformation [37-39]:

$$
\sigma_{f}=\sigma_{0}+k\left(d_{f p}\right)^{-1 / 2}+\alpha G b \rho^{1 / 2}
$$

Eq. 2

where $\sigma_{\mathrm{f}}$ is the strength, $\sigma_{0}$ is a friction stress, $\mathrm{k}$ is the Hall-Petch constant, $\mathrm{d}_{\mathrm{fp}}$ is the mean free path for dislocations, $\alpha$ is a constant and $G$ is the shear modulus, $b$ is the burgers vector and $\rho$ is the dislocation density. We can tell from Eq. 2 that as the dislocation mean free path decreases and the dislocation density increases, the material hardness increases. In this section, the strengthening mechanisms at different layers will be systematically discussed.

Top layer: strengthening by nanoscale martensitic grains. It is widely known that nanoscale grains can significantly improve the hardness and strength of metallic materials. In the SS 304 samples processed by UNSM, nanoscale grains extend from the top surface to 10 $\mu \mathrm{m}$ below the surface. The sizes of the grains are in the range of a few to $10 \mathrm{~s}$ of nanometers. Due to the existence of high density of grain boundaries, the mean free path for dislocations is significantly reduced and thus the alloy strength is improved significantly (Eq. 3). In 
addition, the martensite phase, which extends from the top surface to $50 \mu \mathrm{m}$ below surface and has high strength, also improves strength.

Subsurface: Strengthening by heavily dislocated twin boundaries. In the material's subsurface regions, highly dense deformation twins exist (Fig. 8 and Fig. 9). For polycrystalline materials without twin boundaries, the mean free path $d_{f p}$ is equal to mean grain size $d$. For materials with twin boundaries, the mean free path $d_{f p}$ is smaller than the mean grain size due to the interaction between dislocations and twin boundaries, i.e., dislocations will be blocked by the discontinuity in the slip systems at the two sides of the symmetrical twin boundaries. This means the twin boundaries, like the grain boundaries, can also block dislocation movement and thus improve material strength. As a result, the mean free path of dislocations will be significantly decreased by the presence of the twin boundaries. The effective free path considering both the grain boundaries and the twin boundaries can be expressed by [40]:

$\frac{1}{d_{f p}}=\frac{1}{d_{t w i n}}+\frac{1}{d_{s u b}}$,

Eq. 3

where $\mathrm{d}_{\mathrm{twin}}$ and $\mathrm{d}_{\text {sub }}$ are the average twin and subgrain boundary distances, respectively. From Eq. 3, it can be concluded that the existence of very fine scale twins and numerous twin boundaries in the subsurface regions generated by UNSM can effectively decrease the mean free path of the dislocations through dislocation-twin interaction and thus improve material strength.

\section{Ductility:}

Structural applications require material to possess both high strength and high ductility. The ductility is related to the inhibition of necking and strain localization, which is affected by material work hardening capacity. Work hardening can effectively prevent localized deformation and thus delay necking during tensile test [28]. According to the Considère criterion [56,57], the uniform elongation holds in a tensile test until the onset of the localized deformation, which is governed by

$\left(\frac{\partial \sigma}{\partial \epsilon}\right)_{\dot{\varepsilon}}=\sigma \quad$ Eq. 4

where $\sigma$ is true stress, $\varepsilon$ is true strain and $\dot{\varepsilon}$ is the strain rate. From this equation, we can tell that ductility of the material is essentially determined by its strain hardening capacity, which is the capacity to accumulate dislocations generated during plastic deformation. This requires, firstly, dislocation emission sources, and secondly that the dislocations generated can be preserved. During plastic deformation, dislocation multiplication and annihilation occurs simultaneously. In metallic materials with coarse grains, dislocation accumulates through lattice dislocation storage. For example, a classic Frank-Read source can effectively generate dislocations and thus sustain the plastic deformation [58]. For nano-grained materials, however, most dislocation sources are not operative [26], and thus cannot supply enough dislocations to sustain the plastic deformation. In addition, dislocations cannot be 
properly stored because they tend to disappear at the nanoscale grain boundaries, which often serve as sinks for dislocation annihilation $[30,59,60]$. This often leads to low ductility of the nanostructured materials.

However, in the SS 304 processed by UNSM in this study, the strength has been increased from $340 \mathrm{MPa}$ to $630 \mathrm{MPa}$ while still preserving significant amount of ductility (Fig. 12). To understand why the SS 304 processed by UNSM possesses both high strength and high ductility, it is first necessary to study its overall microstructure. As presented in Fig. 14a, SS 304 after UNSM processing on both sides features a multi-layer (yet integral) metallic component with two strong nanocrystalline surface layers connected by a ductile interior with gradually decreasing martensite volume fraction (Fig. 1b) and increasing grain size. The two nanocrystalline surface layers harden the material and thus significantly improve material strength while the unaffected inner layer provides a ductile interior for dislocation accumulation during tensile deformation. In addition, the highly dense twin boundaries in the subsurface layers can act both as dislocation barriers and dislocation emission sources. It has been reported that the twin boundaries can effectively toughen the materials by providing dislocation nucleation sites through dislocation-TBs interaction [26,61-63]. The interaction between dislocations and the twin boundaries has been intensively studied in the literature [58,64-66]. When a gliding dislocation encounters a twin boundary, stress concentration leads to the generation of new dislocations on the other side of the boundary (Fig. 14b) [26]. This makes the twin boundaries effective sources for dislocation generation, and thus provide efficient dislocation emission sources, toughening the materials [67]. In this way, the deformation twins at material subsurface can serve both as dislocation movement blockers and dislocation emission sources. This means that the twin boundaries first act as dislocation barriers and thus strengthen the materials; at the same time, the twin boundaries can serve as dislocation emission sources and thus provide more mobile dislocations (Fig. 14b) to sustain the plastic deformation, improving material ductility [68].

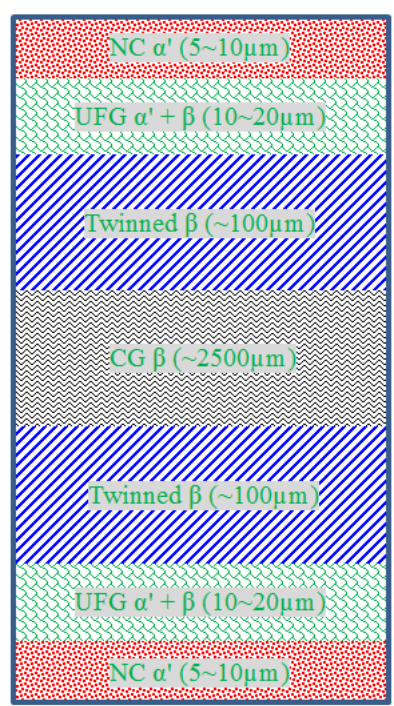

(a)

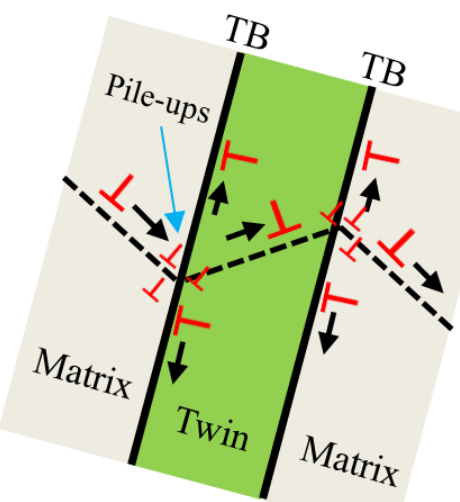

(b)

Fig. 14 (a) Schematic representation of (a) the sandwiched/gradient microstructure in SS 304 processed by UNSM (redrawn with permission from [32]) and (b) dislocation-twinning 
interaction (redrawn with permission from [26]);

In addition, in the center of the material (Fig. 14a), the microstructure is essentially unaffected. This way the dislocation accumulation capacity in material interior is preserved. The unaffected interior on the one hand provides the work-hardening capacity, and on the other hand organically bonds the two surface nanocrystalline surface layer and thus prevents premature necking $[69,70]$, leading to both high strength and high ductility. In addition, the gradually changing martensite distribution ensures strong interfacial strength between the ductile interior and the two nanocrystalline surface layers [7]. Finally, the high magnitude of compressive residual stress can also delay crack propagation [71,72] and thus contributes favorably to material ductility. The comprehensive effects of all these factors lead to both high strength and high ductility in the UNSM samples.

\section{Conclusion:}

UNSM processing of SS 304 was carried out in this study. The results have shown that this process leads to high levels of near-surface compressive residual stresses and dramatic changes in microstructure and hence local and bulk mechanical properties. After UNSM, the material assumes a multi-layer microstructure with two strong nanocrystalline surface layers and a ductile interior with gradually changing martensite volume fraction. The two nanocrystalline surface layers with high martensite content provide strong resistance to plastic flow and thus lead to high yield strength while the unaffected interior provides strain hardening capacity and thus preserves the high ductility. In the subsurface regions of the material, highly dense deformation twins are generated. These deformation twins significantly improve material hardening capacity by acting both as dislocation blockers and dislocation emission sources, and thus strengthening the material while providing enough strain hardening capacity. Furthermore, the gradually changing martensite volume fraction ensures strong interfacial strength between the ductile interior and the two nanocrystalline surface layers and thus prevents early necking. The unique microstructure with a compliant interior sandwiched by two strong nanocrystalline layers leads to both high material strength and high ductility. In addition, the work-hardened surface layer and the high magnitude of compressive residual stress lead to significantly improvement in fatigue properties. It can be concluded that UNSM is a superior surface processing technique that can generate unique microstructure for improved properties and performance. Finally, UNSM can be easily integrated into modern manufacturing system and has great potential in the industry.

\section{ACKNOWLEDGEMENTS}

The authors are grateful for financial support of this research by the Nuclear Energy University Program (NEUP) of the US Department of Energy contract \#102835 issued under prime contract DE-AC07-05ID14517 to Battelle Energy Alliance, LLC. We also gratefully acknowledge the contribution of the State of Ohio, Department of Development and Third 
Frontier Commission, which provided funding in support of "Ohio Center for Laser Shock Processing for Advanced Materials and Devices" and the experimental and computational equipment in the Center that was used in this work. The work performed at the University of Pittsburgh received part support from the National Science Foundation (NSF-DMR-11005757) and the Nuclear Regulatory Commission (NRC-38-09-935). Any opinions, findings, conclusions, or recommendations expressed in these documents are those of the author(s) and do not necessarily reflect the views of the DOE, State of Ohio, Department of Development, the National Science Foundation and the Nuclear Regulatory Commission.

\section{References}

[1] K. Lu, J. Lu, Mater. Sci. Eng. A 375-377 (2004) 38.

[2] H.W. Zhang, Z.K. Hei, G. Liu, J. Lu, K. Lu, Acta Mater. 51 (2003) 1871.

[3] H.L. Chan, H.H. Ruan, a. Y. Chen, J. Lu, Acta Mater. 58 (2010) 5086.

[4] G. Liu, S.. Wang, X.. Lou, J. Lu, K. Lu, Scr. Mater. 44 (2001) 1791.

[5] G. Liu, J. Lu, K. Lu, Mater. Sci. Eng. A 286 (2000) 91.

[6] N.R. Tao, M.L. Sui, J. Lu, K. Lua, Nanostructured Mater. 11 (1999) 433.

[7] J.Z. Lu, K.Y. Luo, Y.K. Zhang, C.Y. Cui, G.F. Sun, J.Z. Zhou, L. Zhang, J. You, K.M. Chen, J.W. Zhong, Acta Mater. 58 (2010) 3984.

[8] J.Z. Lu, K.Y. Luo, Y.K. Zhang, G.F. Sun, Y.Y. Gu, J.Z. Zhou, X.D. Ren, X.C. Zhang, L.F. Zhang, K.M. Chen, C.Y. Cui, Y.F. Jiang, a. X. Feng, L. Zhang, Acta Mater. 58 (2010) 5354.

[9] C. Ye, Y. Liao, G.J. Cheng, Adv. Eng. Mater. 14 (2010) 291.

[10] C. Ye, S. Suslov, B.J. Kim, E. a. Stach, G.J. Cheng, Acta Mater. 59 (2011) 1014.

[11] A.S. Gill, Z. Zhou, U. Lienert, J. Almer, D.F. Lahrman, S.R. Mannava, D. Qian, V.K. Vasudevan, J. Appl. Phys. 111 (2012) 084904.

[12] A. Gill, A. Telang, S.R. Mannava, D. Qian, Y.-S. Pyoun, H. Soyama, V.K. Vasudevan, Mater. Sci. Eng. A 576 (2013) 346.

[13] J.Z. Lu, H. Qi, K.Y. Luo, M. Luo, X.N. Cheng, Corros. Sci. 80 (2014) 53.

[14] K.Y. Luo, J.Z. Lu, Q.W. Wang, M. Luo, H. Qi, J.Z. Zhou, Appl. Surf. Sci. 285 (2013) 607. 
[15] Z.B. Wang, J. Lu, K. Lu, Surf. Coatings Technol. 201 (2006) 2796.

[16] J.Z. Lu, K.Y. Luo, F.Z. Dai, J.W. Zhong, L.Z. Xu, C.J. Yang, L. Zhang, Q.W. Wang, J.S. Zhong, D.K. Yang, Y.K. Zhang, Mater. Sci. Eng. A 536 (2012) 57.

[17] S. Jelliti, C. Richard, D. Retraint, T. Roland, M. Chemkhi, C. Demangel, Surf. Coatings Technol. 224 (2013) 82 .

[18] S. Faghihi, a. P. Zhilyaev, J. a. Szpunar, F. Azari, H. Vali, M. Tabrizian, Adv. Mater. 19 (2007) 1069.

[19] Y.H. Zhao, X.Z. Liao, S. Cheng, E. Ma, Y.T. Zhu, Adv. Mater. 18 (2006) 2280.

[20] R. Song, D. Ponge, D. Raabe, Acta Mater. 53 (2005) 4881.

[21] R. Song, D. Ponge, D. Raabe, Scr. Mater. 52 (2005) 1075.

[22] Z. Horita, K. Ohashi, T. Fujita, K. Kaneko, T.G. Langdon, Adv. Mater. 17 (2005) 1599.

[23] S. Cheng, Y.H. Zhao, Y.T. Zhu, E. Ma, Acta Mater. 55 (2007) 5822.

[24] W.W. Jian, G.M. Cheng, W.Z. Xu, H. Yuan, M.H. Tsai, Q.D. Wang, C.C. Koch, Y.T. Zhu, S.N. Mathaudhu, Mater. Res. ... 1 (2013) 61.

[25] H.T. Wang, N.R. Tao, K. Lu, Scr. Mater. (2012) 1.

[26] K. Lu, L. Lu, S. Suresh, Sci. 324 (2009) 349.

[27] L. Lu, X. Chen, X. Huang, K. Lu, Sci. 323 (2009) 607.

[28] T.H. Fang, W.L. Li, N.R. Tao, K. Lu, Science 331 (2011) 1587.

[29] Y. Wang, M. Chen, F. Zhou, E. Ma, Nature 419 (2002) 912.

[30] Y.M. Wang, E. Ma, Acta Mater. 52 (2004) 1699.

[31] K. Edalati, S. Toh, H. Iwaoka, M. Watanabe, Z. Horita, D. Kashioka, K. Kishida, H. Inui, Scr. Mater. 67 (2012) 814 .

[32] A.Y. Chen, H.H. Ruan, J.B. Zhang, X.R. Liu, J. Lu, Mater. Chem. Phys. 129 (2011) 1096.

[33] P. V Liddicoat, X.-Z. Liao, Y. Zhao, Y. Zhu, M.Y. Murashkin, E.J. Lavernia, R.Z. Valiev, S.P. Ringer, Nat. Commun. 1 (2010) 63.

[34] K. Tai, M. Dao, S. Suresh, A. Palazoglu, C. Ortiz, Nat. Mater. 6 (2007) 454.

[35] R.K. Nalla, J.H. Kinney, R.O. Ritchie, Nat. Mater. 2 (2003) 164. 
[36] S. Kamat, X. Su, R. Ballarini, A.H. Heuer, Nature 405 (2000) 1036.

[37] B.J.F. Bruet, J. Song, M.C. Boyce, C. Ortiz, Nat. Mater. 7 (2008) 748.

[38] A.Y. Chen, H.H. Ruan, J. Wang, H.L. Chan, Q. Wang, Q. Li, J. Lu, Acta Mater. 59 (2011) 3697.

[39] Y. Pyoun, I. Cho, C. Suh, J. Park, Shotpeener.com (n.d.) 2.

[40] A. Cherif, Y. Pyoun, B. Scholtes, J. Mater. Eng. Perform. 19 (2009) 282.

[41] X.J. Cao, Y.S. Pyoun, R. Murakami, Appl. Surf. Sci. 256 (2010) 6297.

[42] A. Amanov, O. V. Penkov, Y.-S. Pyun, D.-E. Kim, Tribol. Int. 54 (2012) 106.

[43] H. Huang, J. Ding, P.G. McCormick, Mater. Sci. Eng. A 216 (1996) 178.

[44] B.D. Cullity, Elements of X-Ray Diffraction, 2nd ed., Addison-Wesley Publishing Company, Inc., Reading, MA, 1978.

[45] Y. Idell, G. Facco, a. Kulovits, M.R. Shankar, J.M.K. Wiezorek, Scr. Mater. 68 (2013) 667.

[46] L. Yang, N.R. Tao, K. Lu, L. Lu, Scr. Mater. 68 (2013) 801.

[47] J.W. Christian, S. Mahajan, Prog. Mater. Sci. 39 (1995) 1.

[48] K. Wang, N.R. Tao, G. Liu, J. Lu, K. Lu, Acta Mater. 54 (2006) 5281.

[49] R. Valiev, Nat Mater 3 (2004) 511.

[50] Y. Iwahashi, Z. Horita, M. Nemoto, T.G. Langdon, Acta Mater. 46 (1998) 3317.

[51] S. Qu, X.H. An, H.J. Yang, C.X. Huang, G. Yang, Q.S. Zang, Z.G. Wang, S.D. Wu, Z.F. Zhang, Acta Mater. 57 (2009) 1586.

[52] Y.S. Li, N.R. Tao, K. Lu, Acta Mater. 56 (2008) 230.

[53] C.X. Huang, Y.L. Gao, G. Yang, S.D. Wu, G.Y. Li, S.X. Li, J. Mater. Res. 21 (2006) 1687.

[54] C. Ye, S. Suslov, D. Lin, G.J. Cheng, Philos. Mag. 92 (2012) 1369.

[55] J. Fan, T. Fu, Mater. Sci. Eng. A 552 (2012) 359.

[56] G. Dieter, Mechanical Metallurgy, 3rd ed., McGraw-Hill Science, New York, 1986.

[57] Y.M. Wang, E. Ma, Mater. Sci. Eng. A 375-377 (2004) 46.

[58] Z.X. Wu, Y.W. Zhang, D.J. Srolovitz, Acta Mater. 57 (2009) 4508. 
[59] M.A. Meyers, A. Mishra, D.J. Benson, Prog. Mater. Sci. 51 (2006) 427.

[60] E. Ma, Scr. Mater. 49 (2003) 663.

[61] M. Dao, L. Lu, Y.F. Shen, S. Suresh, Acta Mater. 54 (2006) 5421.

[62] X. Li, Y. Wei, L. Lu, K. Lu, H. Gao, Nature 464 (2010) 877.

[63] H. Zhou, S. Qu, W. Yang, Model. Simul. Mater. Sci. Eng. 18 (2010) 65002.

[64] Y.T. Zhu, X.L. Wu, X.Z. Liao, J. Narayan, L.J. Kecskés, S.N. Mathaudhu, Acta Mater. 59 (2011) 812.

[65] Z.-H. Jin, P. Gumbsch, K. Albe, E. Ma, K. Lu, H. Gleiter, H. Hahn, Acta Mater. 56 (2008) 1126.

[66] Z.-H. Jin, P. Gumbsch, E. Ma, K. Albe, K. Lu, H. Hahn, H. Gleiter, Scr. Mater. 54 (2006) 1163.

[67] R.J. Asaro, S. Suresh, Acta Mater. 53 (2005) 3369.

[68] Y.B. Wang, M.L. Sui, Appl. Phys. Lett. 94 (2009) 021909.

[69] N. Lu, X. Wang, Z. Suo, J. Vlassak, J. Mater. Res. 24 (2009) 379.

[70] Y. Xiang, T. Li, Z. Suo, J.J. Vlassak, Appl. Phys. Lett. 87 (2005).

[71] D.J. Green, R. Tandon, V.M. Sglavo, Sci. 283 (1999) 1295.

[72] M.P. Rao, A.J. Sánchez-Herencia, G.E. Beltz, R.M. McMeeking, F.F. Lange, Sci. 286 (1999) 102. 